\title{
Pobreza e indigencia en Argentina: construcción de una serie completa y metodológicamente homogénea
}

\section{Poverty and indigence in Argentina: construction of a complete and methodologically homogeneous series}

\author{
Guido Zack ${ }^{1}$ \\ Instituto Interdisciplinario de Economía Política de Buenos Aires (IIEP-BAIRES), \\ CONICET - Universidad de Buenos Aires, Buenos Aires, Argentina \\ Universidad de San Martín (UNSAM), Escuela de Economía y Negocios (EEyN), \\ Centro de Investigaciones Macroeconómicas para el Desarrollo (CIMaD), Buenos Aires, Argentina \\ zack.gui@gmail.com \\ https://orcid.org/0000-0002-5428-3240 \\ Daniel Schteingart ${ }^{2}$ \\ Centro de Innovación de los Trabajadores - Universidad Metropolitana \\ para la Educación y el Trabajo, Buenos Aires, Argentina \\ danyscht@hotmail.com \\ https://orcid.org/0000-0003-2805-883X

\section{Federico Favata ${ }^{3}$} \\ Universidad de San Martín (UNSAM), Escuela de Economía y Negocios (EEyN), \\ Centro de Investigaciones Macroeconómicas para el Desarrollo (CIMaD), Buenos Aires, Argentina \\ favata.federico@gmail.com \\ https://orcid.org/0000-0003-1020-9900
}

Recibido: 05-06-19

Aprobado: 12-02-20

2 Doctor en Sociología.

3 Licenciado en Economía. 


\section{Resumen}

La Argentina no cuenta con una serie larga y comparable de pobreza. Esto se debe a cambios metodológicos, pero especialmente a la interrupción periódica en la publicación de determinados indicadores y en la realización de la encuesta de ingresos. Este artículo reconstruye una serie de pobreza, bajo la metodología actual del instituto de estadística, para que sea comparable con los datos que publique en el futuro. El principal aporte de este artículo es corregir la calibración de la muestra, imputar ingresos para los casos de no respuesta por el método de hot-deck y, en los casos en los que la encuesta no se realizó, estimar los datos de ingresos a través de fuentes alternativas. Los resultados muestran una fuerte caída en la pobreza entre 2003 y 2011, luego un estancamiento con ciertas oscilaciones hasta 2018, cuando se retoma un aumento hasta la actualidad.

Palabras clave: pobreza; condiciones de vida; necesidades básicas; medición de la pobreza; Argentina.

Clasificación JEL: C80; I32.

\section{Abstract}

Argentina does not have a long and comparable range of poverty. This is due to methodological changes, but especially to the periodic interruption in the publication of certain indicators and in the conduct of the income survey. This article reconstructs a series of poverty, under the current methodology of the statistical institute, so that it is comparable with the data that it publishes in the future. The main contribution of this article is to correct the calibration of the sample, to impute revenues for cases of non-response by the hot-deck method and, in cases where the survey was not conducted, to estimate the income data through alternative sources. The results show a sharp drop in poverty between 2003 and 2011, then a stagnation with certain oscillations until 2018, when an increase to the present is resumed.

Keywords: poverty; living conditions; basic needs; poverty measurement; Argentina.

JEL classification: C80; I32. 


\section{Introducción}

Entre 2007 y 2015, el Instituto Nacional de Estadísticas y Censos de la República Argentina (INDEC) subestimó las cifras de inflación. Dado que los datos de precios son indispensables para el cálculo de la canasta básica total (CBT) y alimentaria (CBA), estas se vieron también subestimadas, lo que dio como resultado tasas de pobreza e indigencia muy menores a las reales. Incluso, el gobierno entrante de finales de 2015 tomó la decisión de no publicar la Encuesta Permanente de Hogares (EPH), para los últimos dos trimestres de 2015 , y retomarla recién en el segundo trimestre de 2016, una vez que el INDEC se encontrara en condiciones de hacer la encuesta con la calidad necesaria.

Como resultado, durante esos años, el debate acerca de la pobreza e indigencia en la Argentina giró más en torno a cuál era su nivel real que a las formas de reducirla. En efecto, una serie de instituciones -entre las que se destacan el Centro de Investigación y Formación de la República Argentina (CIFRA-CTA) y el Centro de Estudios Distributivos, Laborales y Sociales (CEDLAS)- realizaron estimaciones de pobreza e indigencia, a partir de la EPH, pero corrigiendo los datos de la CBA y CBT por fuentes de precios alternativas. Por su parte, el Observatorio de la Deuda Social Argentina, de la Universidad Católica Argentina (ODSA-UCA), también se ha encargado de publicar datos de pobreza e indigencia, tomando tanto la EPH como una muestra propia, cuyos resultados no son comparables con los resultantes de la EPH.

En 2016, una vez normalizadas las estadísticas de precios, se volvieron a publicar datos oficiales de pobreza e indigencia, los cuales se situaron muy por encima de las estimaciones alternativas. Mientras que el CIFRA-CTA (2015) estimaba la pobreza del primer semestre de 2015 en $19,7 \%$ de la población y la indigencia en $4,5 \%$, en línea con otros trabajos, como Beccaria y Maurizio (2017) y Zack (2016), el INDEC informó que durante el segundo trimestre de 2016 estas tasas se ubicaron en 32,2\% y $6,3 \%$, respectivamente ${ }^{4}$. ¿Puede la pobreza haber aumentado más de 10 puntos porcentuales en solo un año? ¿Por qué la pobreza aumentó tanto más que la indigencia?

La respuesta es que las series que difundió el INDEC en 2016 no son comparables con los datos previos. El motivo es que se realizó una actualización metodológica de varios aspectos, entre los que se encuentran una nueva especificación de las necesidades energéticas en términos de adulto equivalente; la utilización de una CBA y CBT específica para cada región (en lugar de usar la canasta del Gran Buenos Aires -GBA- para todo el país); y una actualización en la estructura de consumo, a partir del reemplazo de la Encuesta Nacional de Gastos de los Hogares (ENGHo) de $1985 / 6$ por la de $2004 / 5$. Esta última modificación, la que más diferencias genera en los datos de pobreza, implica dos cosas. La primera, la inclusión y exclusión de algunos bienes en la CBA y el cambio en la contribución de muchos de los productos preexistentes en el total de la canasta. La segunda, un aumento en la inversa del Coeficiente de Engel (ICE). Dado que todas estas modificaciones metodológicas afectan a las líneas de pobreza e indigencia -pero no al ingreso familiar obtenido a través de las encuestas- es posible replicarlas para los datos pasados y así obtener una serie comparable (para ello, ver CEDLAS, 2018).

En relación con las modificaciones realizadas sobre la encuesta, hasta el tercer trimestre de 2013, el INDEC utilizó información del censo de 2001 para el cálculo de los ponderadores de la EPH, mientras que, entre dicho trimestre y 2015, usó el censo 2010. Dado que las estimaciones sociodemográficas realizadas a partir del censo 2001 se comprobaron distantes del crecimiento poblacional efectivo, el cambio de los ponderadores generó un quiebre en la muestra, que se tradujo en un aumento súbito del peso relativo de los niños y adolescentes

4 Cabe destacar el esfuerzo de otras instituciones en proveer datos de pobreza e indigencia aunque, por cuestiones metodológicas, no comparables con los publicados por el INDEC. Con una muestra propia, el ODSA-UCA (2016) estimaba, para 2015 , una tasa de pobreza de $29 \%$ y de indigencia de $5,3 \%$. Con una canasta de bienes mucho menos ambiciosa (línea de 5,5 dólares por día a paridad de poder adquisitivo de 2011), el CEDLAS suponía una pobreza de $8,3 \%$ para el mismo año. 
en el conjunto de la población. Luego, en el segundo trimestre de 2016, se revisaron nuevamente estos cambios de ponderadores, asimilándose más a la tendencia previa a 2013. Dado que la pobreza es más alta en los menores de 20 años, estos quiebres inciden en la dinámica de la serie (Tornarolli, 2018). Sin embargo, la edad no es la única variable significativa para explicar la pobreza que presenta discontinuidades. En efecto, también se observan en el nivel educativo del jefe del hogar, el tamaño promedio del hogar y la región. Para corregir estos quiebres, en este artículo se proponen una serie de suavizaciones en la evolución de los ponderadores de ciertos grupos poblacionales.

En otro aspecto de la encuesta, hasta el segundo trimestre de 2015, el INDEC corregía la no respuesta de ingresos mediante imputación individual de valores faltantes por el método de hot-deck, mientras que, desde el segundo trimestre 2016, lo ha hecho por reponderación de la muestra. Teniendo en cuenta que estos dos métodos impactan de manera diferente en las estimaciones, es necesario homogeneizar la metodología. Para ello, como el INDEC no provee los datos necesarios para replicar la reponderación de la muestra, siguiendo a Tornarolli (2018), se replicó el cálculo de los datos a partir de 2016 por el método hot-deck y luego se utilizó la diferencia para ajustar las tasas del período 2003-2015.

Finalmente, la serie de microdatos de la EPH posee algunas observaciones faltantes, como el tercer trimestre de 2007 -por no haberse realizado la encuesta en el GBA, debido a un paro del personal$\mathrm{y}$, entre el tercer trimestre de $2015 \mathrm{y}$ el primero de 2016, por la dudosa calidad de las encuestas. Para realizar un cálculo de la variación de los ingresos de las personas durante esos trimestres faltantes, el presente artículo hace uso de fuentes de datos alternativos, como el Sistema Integrado Previsional Argentino (SIPA), la Administración Nacional de la Seguridad Social (ANSES) y la Encuesta Trimestral de Ocupación e Ingresos (ETOI) de la Dirección de Estadísticas de la CABA. Esta corrección a la serie de pobreza e indigencia de la Argentina no se encuentra en otro trabajo previo.

En resumen, el objetivo de este artículo es proveer una serie de pobreza e indigencia para todo el período que abarca la metodología continua, que sea no solo metodológicamente comparable sino también completa. Asimismo, esta serie se calculó con la metodología actual del INDEC, por lo que es también comparable con los datos que publique en el futuro. Si bien ya se han hecho esfuerzos al respecto -como Vera y Salvia (2019), ODSA-UCA (2019), CEDLAS (2018) y Tornarolli (2018)-, el primero no es comparable con los datos del INDEC, por hacerse a partir de una muestra propia; el segundo y el tercero solo corrigen por la actualización metodológica; y el cuarto agrega la corrección por el cambio en la metodología de la imputación de ingresos en los casos de no respuesta. Sin embargo, en ningún caso se estiman las observaciones faltantes de 2007, 2015 y 2016.

El artículo se estructura de la siguiente manera: en la próxima sección, se describen los cambios metodológicos en la medición de la pobreza y la indigencia introducidos por el INDEC en 2016, mientras que en la tercera sección se detalla la recalibración de la EPH para corregir los quiebres muestrales de 2013 y 2016. En la cuarta sección, se homogeneiza el tratamiento de datos faltantes por no respuesta de ingreso. En la quinta sección, se desarrolla la estimación de los valores en los trimestres faltantes. Finalmente, se presentan las reflexiones finales ${ }^{5}$.

\section{La actualización metodológica del cálculo de la pobreza e indigencia de 2016}

Los indicadores de pobreza e indigencia, calculados por el INDEC, se basan en el método indirecto o de "línea". Este método determina, primeramente, el requerimiento energético y las recomendaciones de nutrientes de cada individuo según sexo y edad. Se establece una unidad de referencia, el adulto equivalente -compuesto por las personas de un sexo y rango de edad determinado-, para luego medir al resto de la población en relación con ese adulto equivalente. Hasta la actualización metodológica realizada en 2016 era considerado adulto equivalente todo individuo de sexo masculino, de entre 30 y 59 años, el cual necesitaba 2700

5 Las bases de datos aquí utilizadas se encuentran disponibles en https://drive.google.com/file/d/1]xuCjyKuHZuE9gkVb6SclKs7VzHHwT-/view?usp=sharing

sociedad y economía • e-ISSN: 2389-9050 • No. 40, 2020 • pp. 69-98 
kilocalorías (Kcal) por día para su correcta nutrición y desarrollo.

Aquí se encuentra el primer cambio metodológico que aplicó el INDEC en 2016, aunque su efecto sobre los indicadores sociales es muy marginal. El adulto equivalente pasó a ser todo individuo de sexo masculino de entre 30 y 60 años, y se aumentó su requerimiento energético a 2750 Kcal. También se ajustaron los requerimientos energéticos del resto de la población y se procedió a una mayor especificación. Así, por ejemplo, se desagregó al grupo de mujeres de entre 18 y 59 años en tres: las mujeres de entre 18 y 29 años, entre 30 y 45 años, y entre 46 y 60 años (Tabla A.l del Anexo A).

Una vez establecidos los requerimientos energéticos de todos los grupos poblacionales por sexo y edad, se traducen las kilocalorías necesarias en bienes alimentarios, según el patrón de consumo de la población de referencia que se desprende de la ENGHo. Así surge la CBA, la cual es valuada a precios de mercado, a partir de los datos del Índice de Precios al Consumidor (IPC), obteniéndose como resultado la línea de indigencia. De esta manera, los hogares cuyos ingresos familiares por adulto equivalente no superen esa línea son considerados indigentes.

El segundo cambio fue la actualización del contenido de la CBA. Esto se dio porque se actualizó el patrón de consumo resultante de la ENGHo 1985/6, para pasar a basarse en la ENGHo 2004/5. La diferencia más destacada entre la CBA anterior y la actual fue la incorporación de nuevos productos, como bebidas alcohólicas, pescado, yogur, manteca y fiambres. También se registraron cambios en las cantidades de los bienes: aumentaron el pan, el arroz, los fideos, las hortalizas, las frutas, y la leche, entre otros; mientras que disminuyeron las galletitas dulces, la papa, la batata, el azúcar, la sal gruesa, entre otros (Tabla A.2 del Anexo A).

El siguiente paso es calcular la CBT o línea de pobreza que, además de los productos de la CBA, incluye otros no alimentarios básicos, como ser vestimenta, transporte, educación, salud, etc. Esta se calcula expandiendo la CBA por un coeficiente resultante nuevamente de la ENGHo: se define la población de referencia como aquella cuyo consumo de alimentos satisface las necesidades mínimas alimentarias y se calcula su Coeficiente de Engel, es decir, el cociente entre el gasto en alimentos y el total. A partir de la inversa de este coeficiente (ICE), se determina cuánto mayor debe ser la CBT en relación con la CBA.

La ICE se va actualizando a partir de la variación de precios de los bienes y servicios que componen la CBT, bajo el supuesto de que las cantidades consumidas no se modifican. Así, en caso de que los precios de los alimentos se incrementen en mayor proporción que los precios de los productos no alimentarios, la ICE va a mostrar una baja (y viceversa).

La tercera y posiblemente más significativa actualización metodológica realizada por el INDEC fue el reemplazo de la estimación de la ICE a partir de la ENGHo 1985/6 por la ENGHo 2004/5. Esto genera un importante aumento en la nueva ICE utilizada (INDEC, 2016). Esta mayor ICE no tiene influencia sobre los indicadores de indigencia, pero sí sobre los de pobreza. Este es el principal motivo por el cual el salto en la tasa de pobreza, a partir de la actualización metodológica, es mucho más importante en comparación con el aumento en la tasa de indigencia.

El último cambio metodológico que introdujo el INDEC fue el cálculo de una CBA y CBT específica para cada una de las regiones de la Argentina. Hasta ahora, todos los ingresos de las familias del país se comparaban con las CBA y CBT resultantes de los patrones de consumo del GBA. Pero, a partir de los datos de la ENGHo 2004/5, se confeccionaron tantas CBA como regiones (GBA, Cuyo, Noreste, Noroeste, Pampeana y Patagónica). Asimismo, se calculó una ICE para cada una de ellas, por lo que también se cuenta con una CBT específica a sus patrones de consumo. Cada una de estas canastas se actualiza a partir de las variaciones de los precios de cada una de las regiones (INDEC, 2016).

En definitiva, las actualizaciones metodológicas propuestas por el INDEC para la medición de los indicadores de indigencia y pobreza pueden resumirse en cuatro aspectos: los ajustes en los requerimientos kilo-calóricos de los individuos según sexo y edad; la actualización a partir de la ENGHo 2004/5 de los productos componentes de la CBA y 
su participación en el total del consumo alimentario; la actualización de la ICE, también a partir de los datos resultantes de la ENGHo 2004/5; y, finalmente, la construcción de CBA y CBT regionales.

A continuación, se calculan las tasas de pobreza e indigencia con la metodología tradicional y con la nueva, identificando el impacto de estos cuatro cambios metodológicos. Cabe aclarar que entre 2007 y 2015, período en que el INDEC subestimó la inflación, los valores de la CBA y la CBT se ajustaron mediante el IPC de la provincia de San Luis. A partir de julio de 2012, se sumó el de la Ciudad Autónoma de Buenos Aires y, desde julio de 2013, también el de la provincia de Córdoba. Si bien el INDEC no revisó la serie de IPC de 2007-2015, sí dio una clara pista respecto a lo que pasó en esos años (INDEC, 2016). El organismo señaló que, en diciembre de 2006, con la nueva metodología, la CBA y la CBT del GBA eran de $\$ 149,13$ y $\$ 389,28$ por adulto equivalente, respectivamente; mientras que en abril de 2016 estos valores ascendieron a $\$ 1.514,53$ y $\$ 3.663,66$. De este modo, entre diciembre de 2006 y abril de 2016, la CBA del GBA se multiplicó por 10,16 veces, en tanto que la CBT lo hizo por 9,4l veces. Estas cifras son muy similares a las alcanzadas en este trabajo a partir del nivel general y el rubro de alimentos y bebidas del IPC de las provincias mencionadas. Las pequeñas discrepancias, menores al $3 \%$ en la variación total de esos casi 10 años, fueron prorrateadas proporcionalmente en todos los meses de forma que el punto de partida (diciembre de 2006) y el de llegada (abril de 2016) sean idénticos a los provistos por INDEC (ver Tabla B.l y Tabla B.2 del Anexo B).

\subsection{Evolución de la pobreza y la indigencia según la vieja y la nueva metodología}

Los datos del presente artículo se toman de la serie completa de la EPH en su modalidad continua, una serie trimestral que se inicia en el tercer trimestre de 2003 aunque, como se mencionó, hay algunos trimestres sin información. Los datos se presentan bajo la modalidad de semestres móviles, ya que en los trimestres impares la pobreza tiende a ser menor que en los pares, dada la estacionalidad del medio aguinaldo.

La Figura 1 exhibe la evolución de la tasa de pobreza según la metodología tradicional y la actual. De acuerdo a la metodología anterior, en el segundo semestre de 2003, la pobreza afectaba al $48,2 \%$ de la población, cifra que disminuyó aceleradamente hasta el primer semestre de 2007. Entre 2007 y 2011, la pobreza siguió disminuyendo, aunque más moderadamente, producto de un menor dinamismo económico y una aceleración inflacionaria que morigeró la mejora de los ingresos reales de la población; hasta alcanzar, en el segundo semestre de 2011, al 18,7\% de la población. Entre fines de 2011 y fines de 2013 , la baja continuó, pero fue muy pequeña, para luego incrementarse en más de tres puntos porcentuales (p.p.) en 2014, año de recesión, devaluación y fuerte aceleración inflacionaria. En 2015, la pobreza volvió a caer, aunque la serie se corta en el primer semestre, para aumentar en 2016, bajar en 2017 al piso de 15,6\%, y subir nuevamente a partir de entonces. Si incorporamos los cuatro cambios metodológicos mencionados, observamos una tendencia muy similar, aunque con un nivel mayor en aproximadamente 10 p.p.: el punto de partida de la serie comienza en $57,9 \%$ de pobres y el mínimo del segundo semestre de 2017 se ubica en $\mathbf{2 5 , 7 \%}$.

La Tabla 1 muestra el impacto de los cuatro cambios metodológicos descritos en las cifras de pobreza. En promedio, la metodología nueva introduce unos 10 p.p. de pobres, con un mínimo de 9,1 puntos y un máximo de 11,3. Asimismo, puede notarse que las modificaciones en las tablas de adulto equivalente y la regionalización de las canastas básicas contribuyen a una menor cifra de pobreza, mientras que el cambio de canasta alimentaria y el incremento del componente no alimentario implican fuertes subas.

En la Figura 2, se muestran las tasas de indigencia según la metodología anterior y la nueva. En ambos casos, la tendencia es muy similar, es decir, una fuerte caída hasta 2007, una reducción más moderada hasta 2011 y, luego, oscilaciones hasta empezar a aumentar en 2018, siempre con una diferencia en niveles algo inferior a 1 p.p., en promedio, entre la metodología anterior y la actual. 


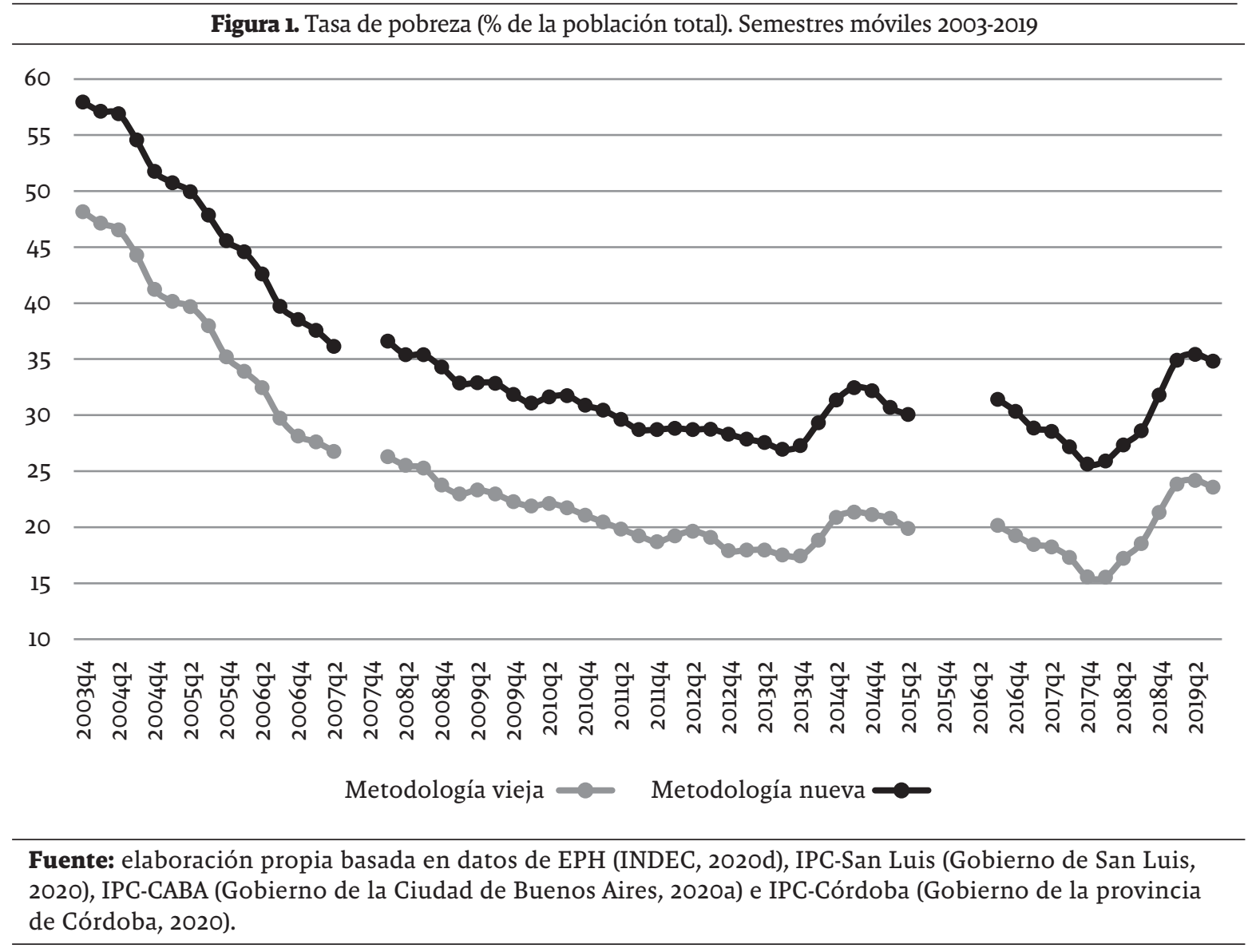

Tabla 1. Incidencia de los cambios metodológicos en la tasa de pobreza (en puntos porcentuales)

\begin{tabular}{c|c|c|c|c|c}
\hline & \multicolumn{5}{|c}{ Efectos } \\
\cline { 2 - 6 } & $\begin{array}{c}\text { Adulto } \\
\text { equivalente }\end{array}$ & $\begin{array}{c}\text { Nueva canasta } \\
\text { alimentaria }\end{array}$ & $\begin{array}{c}\text { Regionalización de } \\
\text { canastas }\end{array}$ & $\begin{array}{c}\text { Cambio en el } \\
\text { coeficiente de Engel }\end{array}$ & $\begin{array}{c}\text { Total cuatro } \\
\text { efectos }\end{array}$ \\
\cline { 2 - 6 } Promedio & $-0,30$ & 4,22 & $-1,33$ & 7,49 & 10,08 \\
Mánimo efecto & $-0,12$ & 3,47 & $-1,01$ & 6,34 & 9,07 \\
& $-0,46$ & 5,30 & $-1,55$ & 8,78 & 11,27 \\
\hline
\end{tabular}

Fuente: elaboración propia basada en datos de EPH (INDEC, 2020d), IPC-San Luis (Gobierno de San Luis, 2020), IPC-CABA (Gobierno de la Ciudad de Buenos Aires, 2020a) e IPC-Córdoba (Gobierno de la provincia de Córdoba, 2020).

La Tabla 2 exhibe la incidencia de los cuatro cambios metodológicos en la tasa de indigencia. En promedio, la nueva metodología introdujo 0,84 p.p. más de indigentes, con un máximo de 1,39 puntos y un mínimo de 0,39. Esto se explica íntegramente porque la nueva canasta alimentaria es más exigente en términos monetarios que la anterior. Por el contrario, las modificaciones en las tablas de adulto equivalente y la regionalización de las canastas alimentarias tienen un efecto a la baja en la tasa de indigencia. Por definición, el cambio del coeficiente de Engel no tiene impacto. 


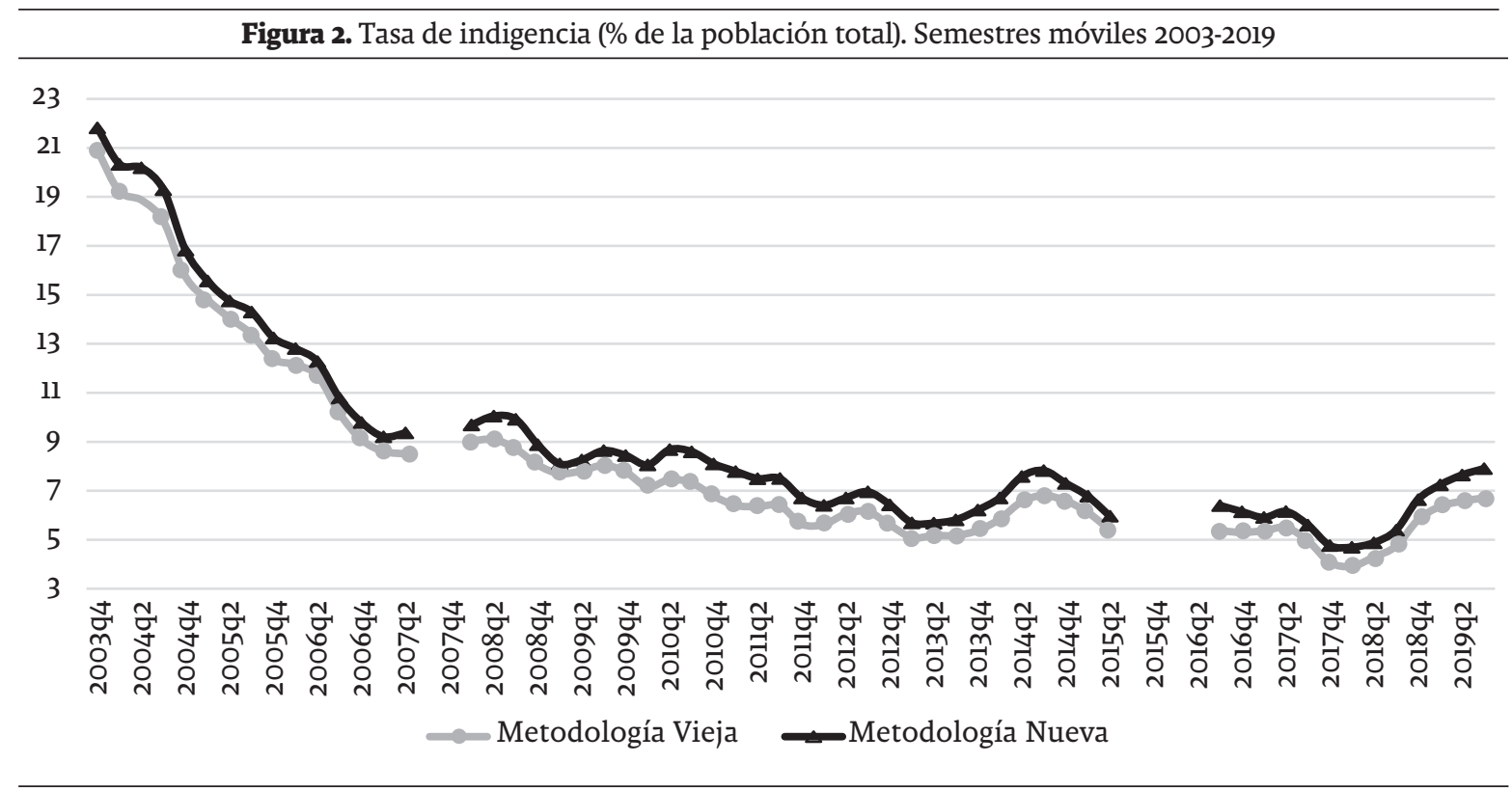

Fuente: elaboración propia basada en datos de EPH (INDEC, 2020d), IPC-San Luis (Gobierno de San Luis, 2020), IPC-CABA (Gobierno de la Ciudad de Buenos Aires, 2020a) e IPC-Córdoba (Gobierno de la provincia de Córdoba, 2020).

Tabla 2. Incidencia de los cambios metodológicos en la tasa de indigencia (en puntos porcentuales)

\begin{tabular}{c|c|c|c|c|c}
\hline & \multicolumn{5}{|c}{ Efectos } \\
\cline { 2 - 6 } & $\begin{array}{c}\text { Adulto } \\
\text { equivalente }\end{array}$ & $\begin{array}{c}\text { Nueva canasta } \\
\text { alimentaria }\end{array}$ & $\begin{array}{c}\text { Regionalización de } \\
\text { canastas }\end{array}$ & $\begin{array}{c}\text { Cambio en el } \\
\text { coeficiente de Engel }\end{array}$ & $\begin{array}{c}\text { Total cuatro } \\
\text { efectos }\end{array}$ \\
\cline { 2 - 6 } Mŕnimo efecto & $-0,17$ & 1,61 & $-0,59$ & 0,00 & 0,84 \\
Máximo efecto & $-0,03$ & 1,01 & $-0,27$ & 0,00 & 0,39 \\
& $-0,43$ & 2,46 & $-0,97$ & 0,00 & 1,39 \\
\hline
\end{tabular}

Fuente: elaboración propia basada en datos de EPH (INDEC, 2020d), IPC-San Luis (Gobierno de San Luis, 2020), IPC-CABA (Gobierno de la Ciudad de Buenos Aires, 2020a) e IPC-Córdoba (Gobierno de la provincia de Córdoba, 2020).

\section{Recalibración de la Encuesta Permanente de Hogares}

La EPH encuesta a unos 18.000 hogares por trimestre, en 31 aglomerados urbanos del país, los cuales representan aproximadamente el $62 \%$ de la población total. El modo en que se muestrea la EPH tiene como pilar los censos nacionales de población y vivienda que se realizan cada diez años. Hasta 2013, la EPH basó sus proyecciones sociodemográficas ${ }^{6}$ en el censo 2001, mientras que, a partir de dicho año, lo hizo con el censo 2010. Sin embargo, las proyecciones realizadas con el censo 2001 tuvieron diferencias con la evolución real de la población evidenciada por el censo 2010. Entre el tercer trimestre de 2013 y el segundo de 2014, el INDEC intentó corregir estas discrepancias, aunque sin un empalme hacia atrás, por lo que se generó un quiebre en los ponderadores muestrales. En la Figura 3, se puede observar que la EPH original presenta un salto significativo en la población de referencia, desde aproximadamente 25.600 .000 personas

6 Las proyecciones sociodemográficas se refieren, entre otras cosas, a cuánto crecerá la población por año en cada aglomerado urbano, cómo será el crecimiento demográfico entre los sexos o cuánto cambiará la composición etaria de la población. 
en el tercer trimestre de 2013, a 26.600.000 personas en el segundo trimestre de 2014 una variación mucho mayor a la observada antes y después de ese período (Arakaki, 2016).

Es particularmente llamativo el salto en la participación de los menores de 20 años en el total de la población desde el tercer trimestre de 2013 (Figura 4). Cuando el INDEC volvió a difundir los microdatos de la EPH en 2016, la participación de los niños y adolescentes retornó a una tendencia similar a la previa. Este salto implica una sobrestimación de la tasa de pobreza, dado que tiende a ser más alta en los menores.

Figura 3. Población de referencia de la EPH original (en miles)

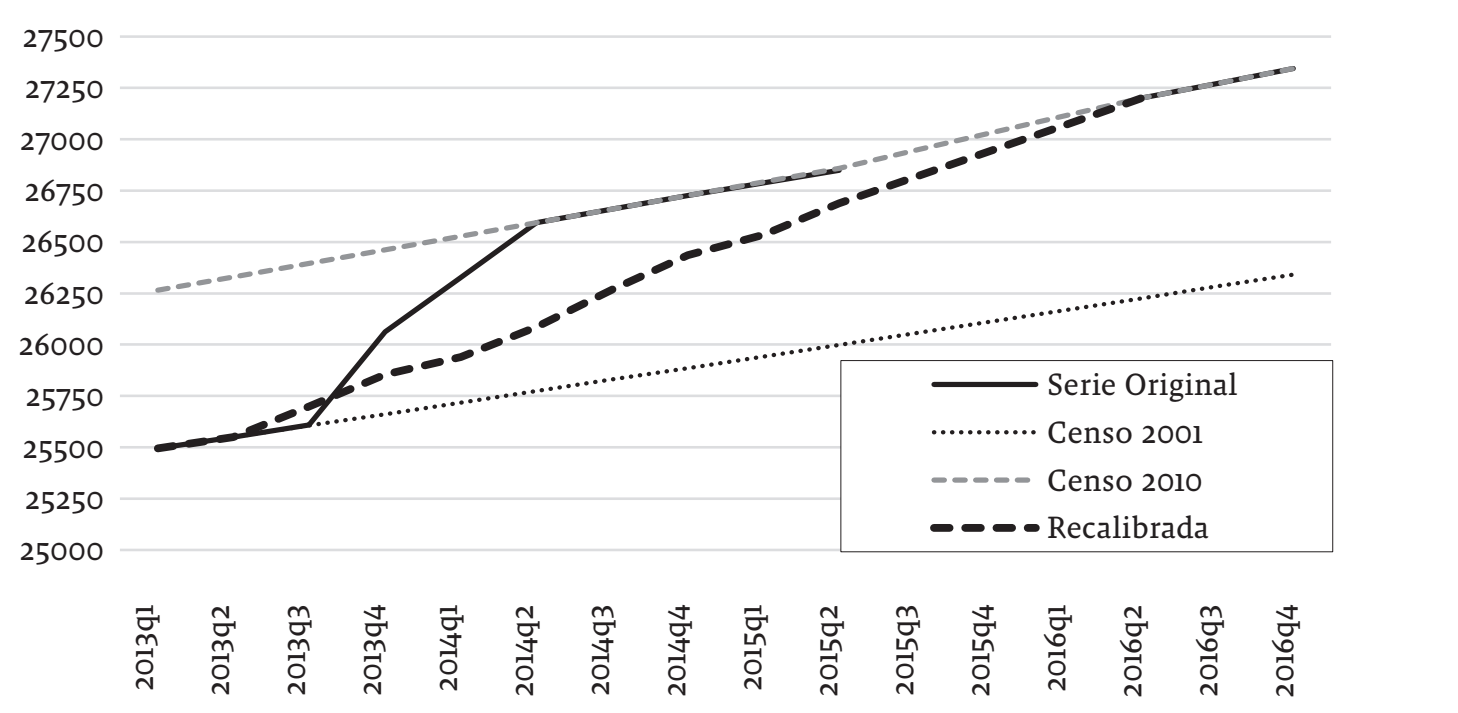

Fuente: elaboración propia basada en datos de EPH (INDEC, 2020d) y Censos Nacionales de Población y Vivienda (INDEC, 2020b).



Fuente: elaboración propia basada en datos de EPH (INDEC, 2020d). 
Asimismo, el cambio muestral de 2013 alteró otras variables sociodemográficas, tales como el número promedio de miembros del hogar, el nivel educativo de los jefes o el peso relativo de cada región en el total. El común denominador de estos cambios fue un aumento del peso relativo de hogares de nivel socioeconómico bajo.

Todo ejercicio de recalibración implica que, al mejorar la calibración de algunas variables, se afecta la de otras. Así, al realizar la recalibración es importante que no se esté afectando variables relevantes. Es por eso que, para evitar los sesgos de la encuesta original, se seleccionaron las variables más relevantes y se procedió de la siguiente manera (Tabla 3). En primer lugar, se estratificó a los hogares a partir de la combinatoria de cinco variables: a) región: CABA, partidos del GBA, Cuyo, Pampeana, Patagonia, NOA y NEA; b) nivel educativo del jefe de hogar: sin instrucción, primaria incompleta, primaria completa, secundaria incompleta, secundaria completa, superior incompleta, superior completa; c) cantidad de menores de 20 años en el hogar: $\mathrm{O}$ a 9 o más; d) cantidad de personas entre 20-60 años en el hogar: 0 a 9 o más; y e) cantidad de personas mayores de 60 años: 0 a 9 o más. De este modo, surgieron 4.895 tipos de hogares, de los cuales el $88,5 \%$ apareció en todos los trimestres comprendidos entre 2012 y 2017.

Para lograr que el $11,5 \%$ restante apareciera en todos los trimestres, se hizo una segunda ronda de clasificación, agrupando cada una de las cinco variables. La clasificación se redujo a: a) región: GBA, norte (NOA y NEA) y resto (Cuyo, Pampeana y Patagonia); b) nivel educativo del jefe de hogar: bajo (hasta secundaria incompleta), medio (secundaria completa) y alto (a partir de superior incompleta); c) cantidad de menores de 20 años en el hogar: $\mathrm{O}$ a 5 o más; d) cantidad de personas entre 20-60 años en el hogar: 0 a 4 o más; y e) cantidad de personas mayores de 60 años: 0 a 3 o más. Con ello se logró estratificar un $7,5 \%$ adicional de hogares.

Para clasificar el $4 \%$ restante de hogares, se realizó una tercera combinatoria en la cual se eliminó el criterio de región, de modo que se estratificaron hogares según las otras cuatro variables agregadas

\begin{tabular}{|c|c|c|c|}
\hline Variables & Combinatoria 1 & Combinatoria 2 & Combinatoria 3 \\
\hline Región & $\begin{array}{c}\text { 1: CABA; 2: Partidos del } \\
\text { GBA; 3: NOA; 4; NEA; 5: } \\
\text { Cuyo; 6: Pampeana; 7: } \\
\text { Patagónica }\end{array}$ & $\begin{array}{l}\text { 1: GBA; 2: NOA-NEA; 3: } \\
\text { Resto }\end{array}$ & Sin clasificar \\
\hline Nivel educativo del jefe & $\begin{array}{l}\text { 1: Sin instrucción; } \\
\text { 2: Primaria incompleta; } \\
\text { 3: Primaria completa; } \\
\text { 4: Secundaria incompleta; } \\
\text { 5: Secundaria completa; } \\
\text { 6: Superior incompleta; } \\
\text { 7: Superior completa }\end{array}$ & $\begin{array}{l}\text { 1: Bajo (hasta sec. incom- } \\
\text { pleta); } \\
\text { 2: Medio (Sec. completa); } \\
\text { 3: Alto (Mayor a Sec. } \\
\text { Completa) }\end{array}$ & $\begin{array}{l}\text { 1: Bajo (hasta sec. incom- } \\
\text { pleta); } \\
\text { 2: Medio (Sec. completa); } \\
\text { 3: Alto (Mayor a Sec. } \\
\text { Completa) }\end{array}$ \\
\hline Menores de 20 años & $\begin{array}{l}\text { o: o menores; } 1: 1 \text { menor } \\
\text { (...); 9: } 9 \text { menores o más }\end{array}$ & $\begin{array}{l}\text { O: o menores; } 1 \text { : } 1 \text { menor } \\
\text { (...); 5:5 menores o más }\end{array}$ & $\begin{array}{l}\text { o: o menores; } 1: 1 \text { menor } \\
\text { (...); 5:5 menores o más }\end{array}$ \\
\hline Personas entre $20-60$ años & $\begin{array}{l}\text { o: o adultos; } 1: 1 \text { adulto (...); } \\
\text { 9: } 9 \text { adultos o más }\end{array}$ & $\begin{array}{c}\text { O: } 0 \text { adultos; } 1: 1 \text { adulto (...); } \\
\text { 4: } 4 \text { adultos o más }\end{array}$ & $\begin{array}{c}\text { O: } 0 \text { adultos; } 1: 1 \text { adulto (...); } \\
\text { 4: } 4 \text { adultos o más }\end{array}$ \\
\hline Mayores de 60 años & $\begin{array}{l}\text { o: o mayores; } 1 \text { : } 1 \text { mayor } \\
\text { (...); 9: } 9 \text { mayores o más }\end{array}$ & $\begin{array}{l}\text { o: o mayores; } 1 \text { : } 1 \text { mayor } \\
\text { (...); 3: } 3 \text { mayores o más }\end{array}$ & $\begin{array}{l}\text { o: o mayores; } 1 \text { : } 1 \text { mayor } \\
\text { (...); 3: } 3 \text { mayores o más }\end{array}$ \\
\hline $\begin{array}{l}\text { Cantidad de tipos de } \\
\text { hogar }\end{array}$ & 4895 & 703 & 275 \\
\hline Total de hogares & $88,5 \%$ & $7,5 \%$ & $3,0 \%$ \\
\hline
\end{tabular}


en las mismas categorías que en la segunda combinatoria. De esta manera, solo el $1 \%$ de los hogares quedó sin estratificar, en cuyo caso se mantuvieron los ponderadores originales de la EPH (Tabla 3).

Una vez estratificados los hogares, se procedió a calcular su evolución entre los cuatro trimestres anteriores al tercero de 2013 y los cuatro trimestres posteriores al segundo de 2016. Para recalibrar la EPH, se calculó un coeficiente de ajuste según estrato de hogar y trimestre, de modo que se exhibieran uniformemente las tendencias entre el período previo y posterior.

La recalibración del peso de los múltiples estratos de hogar implicó una suavización de la cantidad de personas en la EPH (Figura 3), de los menores de 20 años (Figura 4), del nivel educativo de los jefes de hogar (Figura 5) y de la cantidad de personas por hogar (Figura 6).

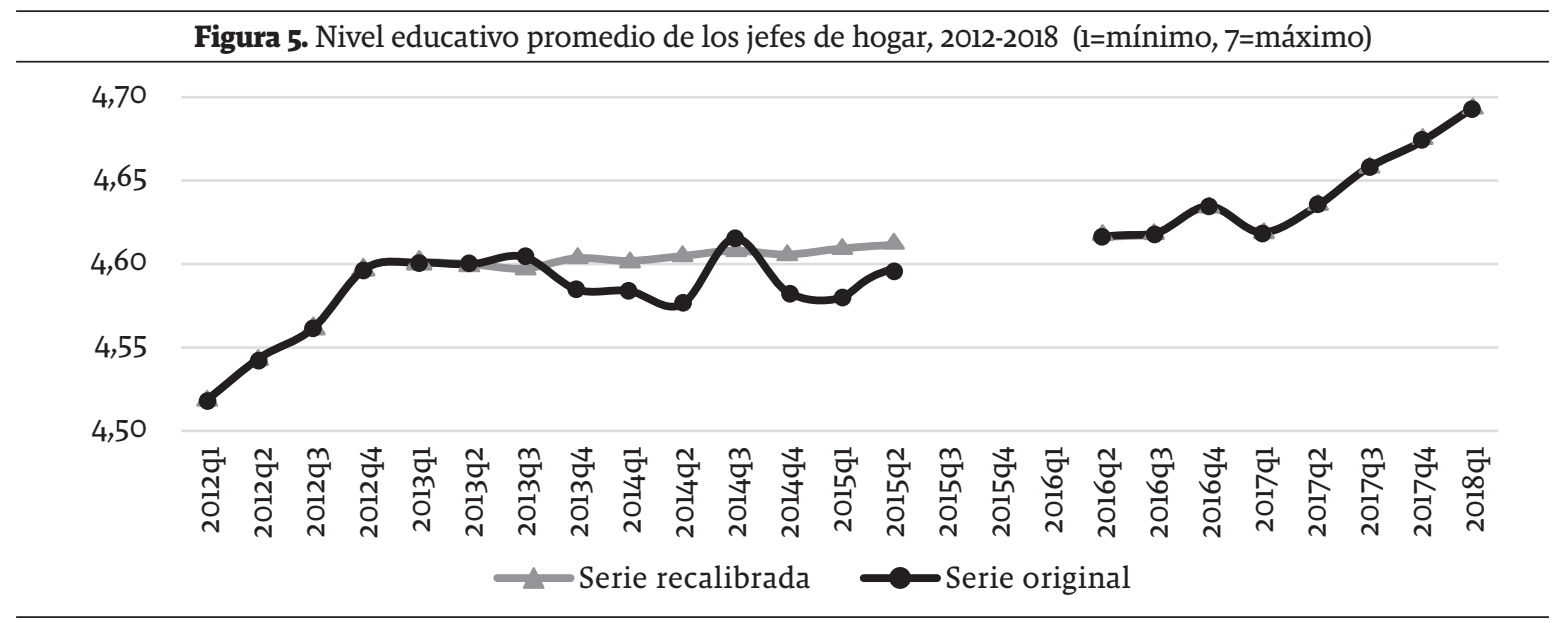

Fuente: elaboración propia basada en datos de EPH (INDEC, 2020d).

Figura 6. Cantidad de personas promedio por hogar, 2012-2018

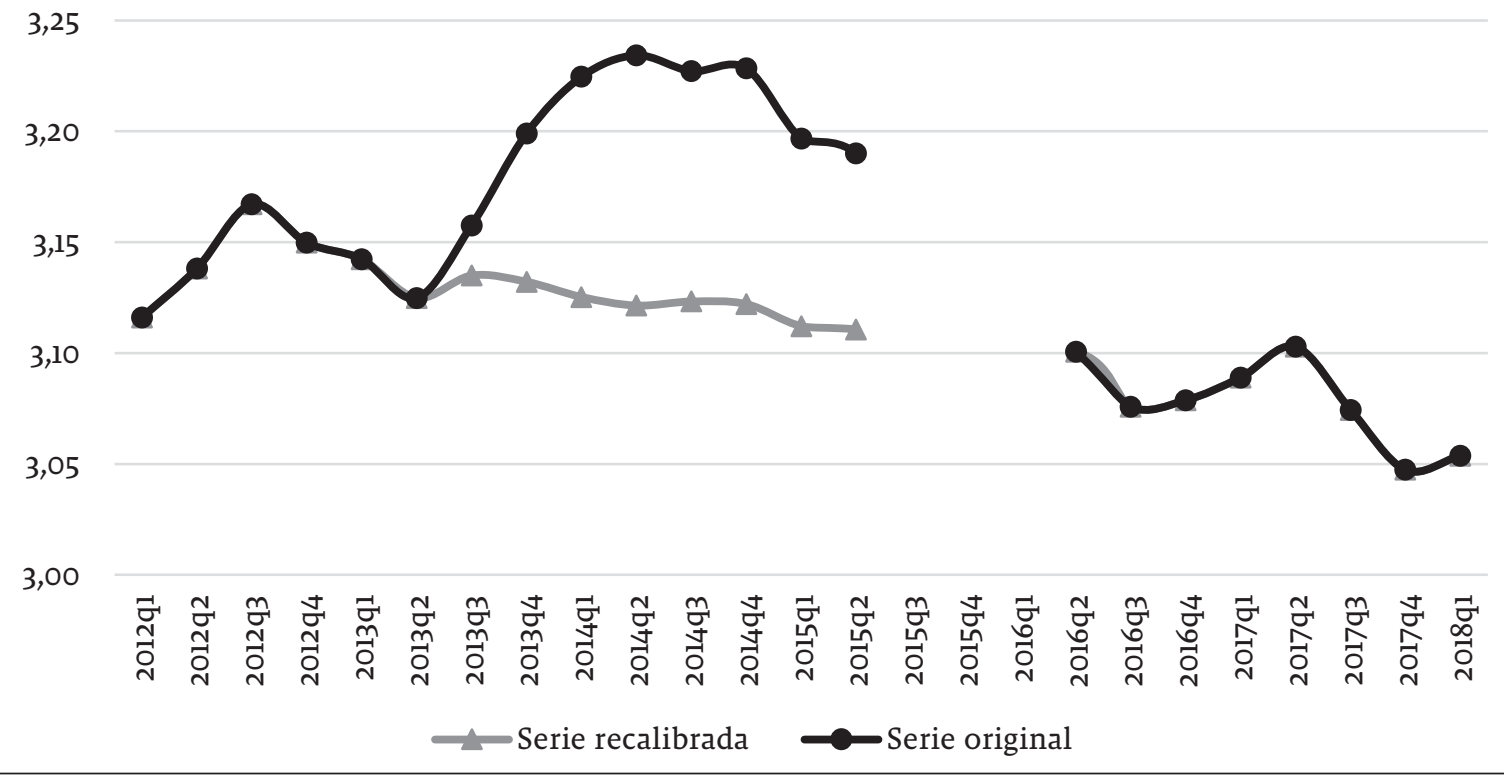

Fuente: elaboración propia basada en datos de EPH (INDEC, 2020d). 
Como se observa en la Figura 7 y la Figura 8, las series recalibradas exhiben una menor pobreza e indigencia que la serie original durante el período 2013-2015. En promedio, el impacto en la pobreza es de 1,2 p.p., con un máximo de 2 puntos en el segundo semestre de 2014. En el caso de la indigencia, el efecto de la recalibración promedia 0,3 p.p. en los trimestres corregidos, con un máximo de 0,5 puntos en el segundo semestre de 2014 .

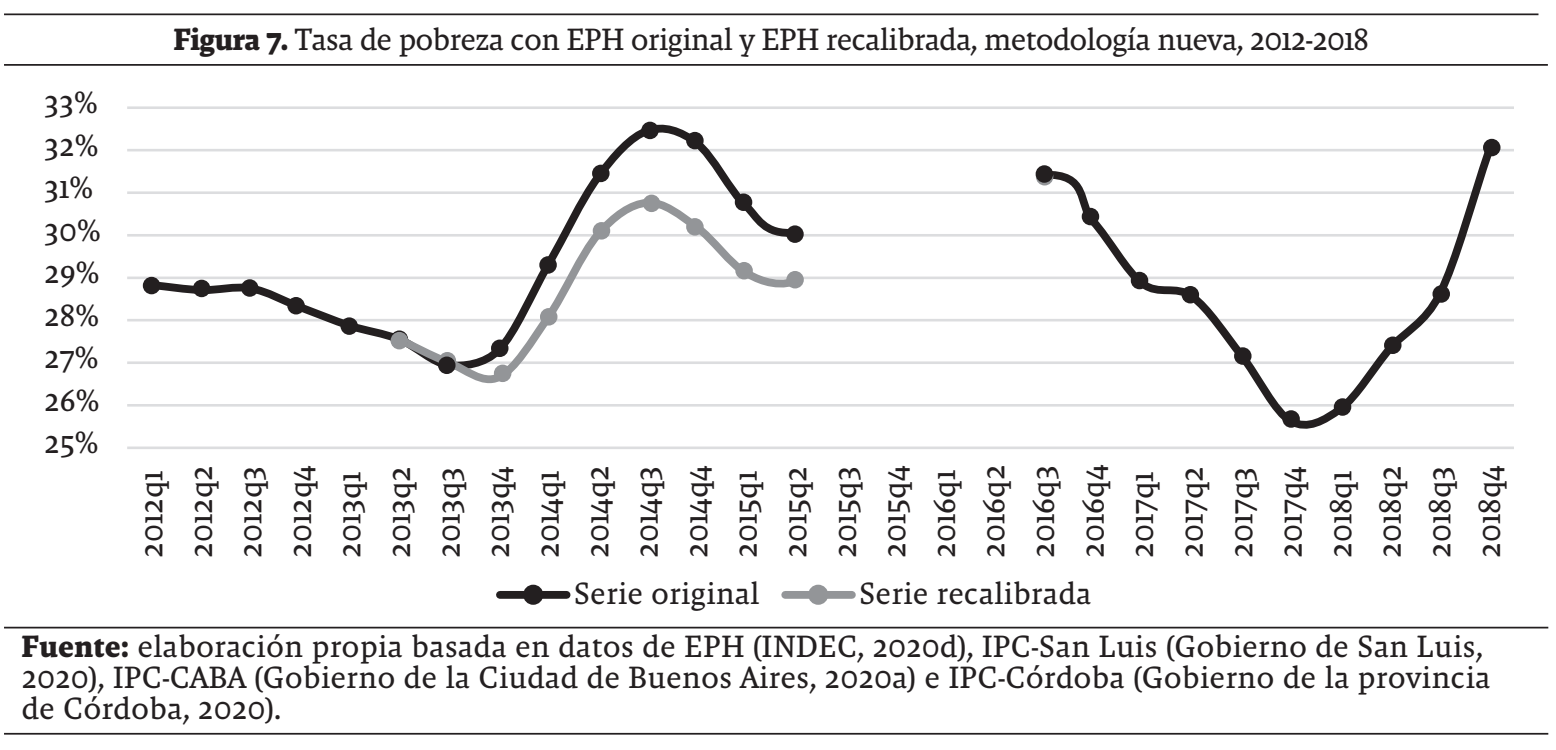

Figura 8. Tasa de indigencia con EPH original y EPH recalibrada, metodología nueva, 2012-2018

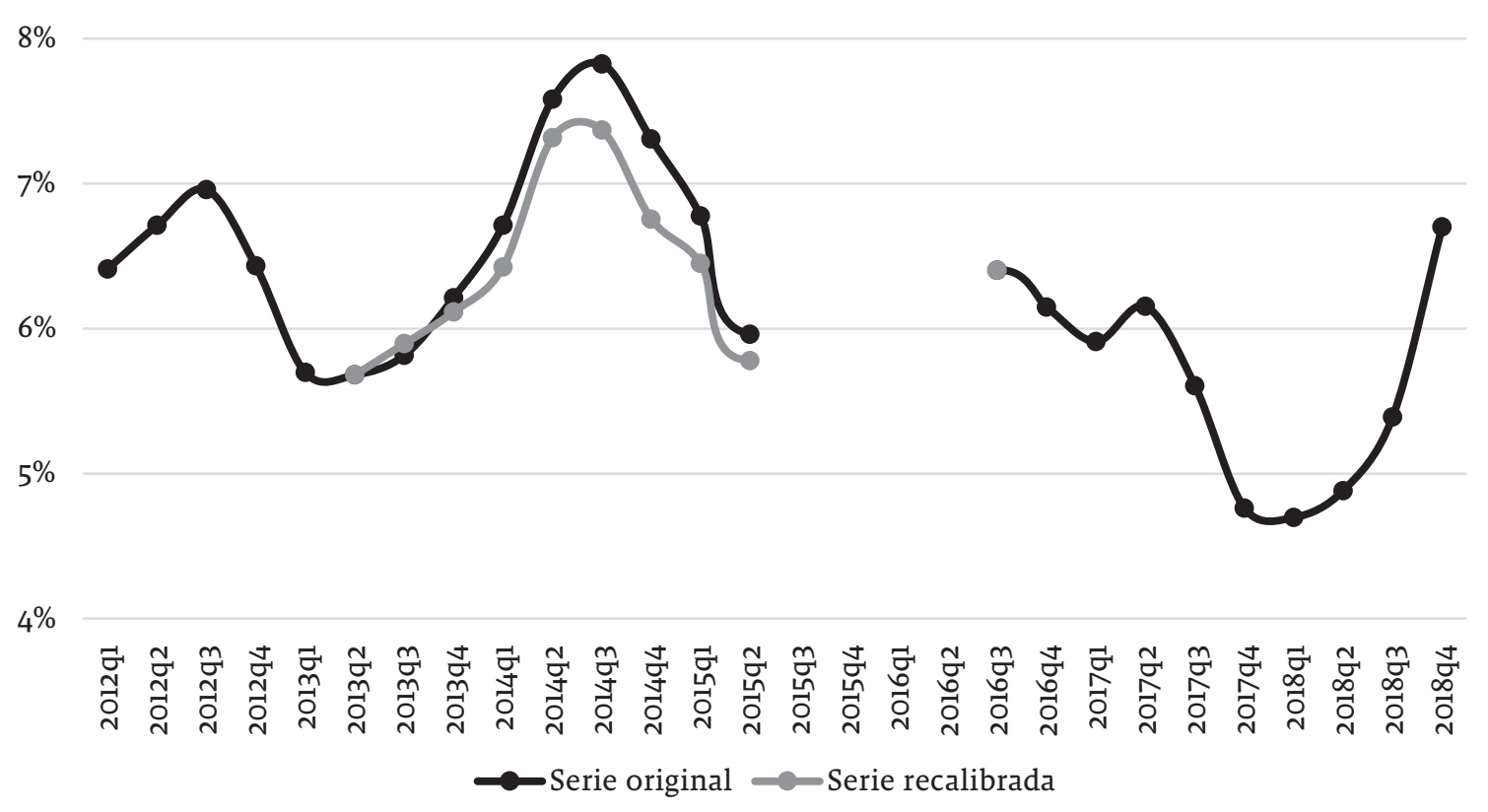

Fuente: elaboración propia basada en datos de EPH (INDEC, 2020d), IPC-San Luis (Gobierno de San Luis, 2020), IPC-CABA (Gobierno de la Ciudad de Buenos Aires, 2020a) e IPC-Córdoba (Gobierno de la provincia de Córdoba, 2020). 


\section{Imputación de ingresos para los casos de no respuesta}

Un problema frecuente en las encuestas de hogares es la no respuesta de ingresos. Esto se debe, en parte, a la desconfianza de los entrevistados, a pesar del secreto estadístico. A partir de 2003, se aplicaron distintos métodos para corregir este problema. En un primer momento, se utilizó el método de "ponderadores específicos" o "reponderación", por medio del cual se crea un ponderador adicional solo para aquellos individuos que declaran ingresos. En 2009, se publicaron nuevas versiones de los microdatos desde 2003, en donde la corrección de la no respuesta ya no se hacía con la reponderación de la muestra, sino con el método de imputación múltiple hot-deck. A partir de 2016, el INDEC -sin modificar los microdatos previos- ha vuelto a utilizar el método de reponderación.

Dado que los datos de pobreza e indigencia son sensibles al método de imputación de ingresos (Tornarolli, 2018), es necesario homogeneizarlo. Esto no pudo realizarse a través del método de ponderadores específicos, dado que no se cuenta con información de las "subpoblaciones de interés". Así, fue necesario reestimar los datos para el período 2016-2018 mediante el método hot-deck. No obstante, el objetivo de este artículo es tener una serie de pobreza e indigencia homogénea con la metodología actual del INDEC, de forma que los datos venideros sean comparables con la serie aquí alcanzada. Así, se decidió mantener los valores de pobreza e indigencia que publica el INDEC en el período 2016-2018 con la metodología oficial, calcular la diferencia porcentual promedio anual con el método hot-deck para dicho período y utilizar ese porcentaje para ajustar las tasas del período 2003-2015, bajo el supuesto de que estas deberían mantenerse relativamente constantes.

El método hot-deck consiste en un proceso por el cual se otorga un valor de ingreso de manera aleatoria para los casos de no respuesta, siendo otorgado por un individuo con cualidades similares que sí declara, denominado donante. Siguiendo la metodología anterior del INDEC (2009), estas cualidades son sexo, rango de edad, rango de horas trabajadas, condición de actividad, calificación, nivel de educación y región. En algunos casos, puede suceder que no haya suficientes donantes para cierto grupo de individuos con determinadas cualidades. En ese caso, se relajan las condiciones de agrupamiento, es decir, se elimina la cualidad considerada menos relevante, en este caso, la variable "región", hasta obtener al menos un donante para cada uno de los individuos que no declaran ingresos. Asimismo, este proceso se realiza para cada una de las categorías de ingresos: ingresos habituales por actividad principal, ingresos no habituales por la actividad principal, ingresos por otras ocupaciones e ingresos no laborales.

En la Tabla 4 se muestra la tasa de pobreza por trimestre entre 2016-18 según los datos oficiales del INDEC, que corrige los casos de no respuesta por ponderadores específicos, y la corrección aquí realizada por hot-deck. En promedio, el método de

Tabla 4. Tasa de pobreza e indigencia según método de imputación de ingresos (ponderadores específicos y hot-deck), 2016-2018

\begin{tabular}{c|ccc|ccc}
\hline & \multicolumn{3}{|c|}{ Pobreza } & \multicolumn{3}{c}{ Indigencia } \\
\hline Trimestre & $\begin{array}{c}\text { Serie original (ponde- } \\
\text { radores específicos) }\end{array}$ & $\begin{array}{c}\text { Estimación } \\
\text { con hot deck }\end{array}$ & $\begin{array}{c}\text { Diferencia } \\
\text { (p.p.) }\end{array}$ & $\begin{array}{c}\text { Serie original (ponde- } \\
\text { radores específicos) }\end{array}$ & $\begin{array}{c}\text { Estimación } \\
\text { con hot deck }\end{array}$ & $\begin{array}{c}\text { Diferencia } \\
\text { (p.p.) }\end{array}$ \\
\hline $2016 q 2$ & $32,17 \%$ & $31,89 \%$ & 0,29 & $6,19 \%$ & $6,10 \%$ & 0,09 \\
$2016 q 3$ & $30,67 \%$ & $29,31 \%$ & 1,36 & $6,61 \%$ & $6,65 \%$ & $-0,04$ \\
$2016 q 4$ & $29,99 \%$ & $28,82 \%$ & 1,17 & $5,68 \%$ & $5,62 \%$ & 0,06 \\
$2017 q 1$ & $27,73 \%$ & $26,78 \%$ & 0,95 & $6,14 \%$ & $6,08 \%$ & 0,06 \\
$2017 q 2$ & $29,39 \%$ & $29,32 \%$ & 0,06 & $6,17 \%$ & $6,46 \%$ & $-0,29$ \\
$2017 q 3$ & $24,95 \%$ & $24,75 \%$ & 0,20 & $5,04 \%$ & $4,60 \%$ & 0,44 \\
$2017 q 4$ & $26,29 \%$ & $25,46 \%$ & 0,83 & $4,48 \%$ & $4,70 \%$ & $-0,22$ \\
$2018 q 1$ & $25,55 \%$ & $25,32 \%$ & 0,22 & $4,91 \%$ & $4,85 \%$ & 0,06 \\
$2018 q 2$ & $29,13 \%$ & $28,70 \%$ & 0,43 & $4,85 \%$ & $4,80 \%$ & 0,05 \\
\hline Promedio & $\mathbf{2 8 , 4 3 \%}$ & $\mathbf{2 7 , 8 2} \%$ & $\mathbf{0 , 6 1}$ & $\mathbf{5 , 5 6 \%}$ & $\mathbf{5 , 5 4 \%}$ & $\mathbf{0 , 0 3}$ \\
\hline
\end{tabular}

Fuente: elaboración propia basada en datos de EPH (INDEC, 2020d). 
ponderadores específicos añadió 0,61 p.p. más de pobres que el hot-deck, es decir un 2,2\% más En el caso de la indigencia, la diferencia es mínima. Este porcentaje es el que se utiliza para corregir los datos de 2003-2015.

En la Figura 9 se puede observar la evolución de la tasa de pobreza con la homogeneización del método de imputación de ingresos y sin tal homogeneización. La máxima diferencia es de 1,4 p.p. hacia 2003-4. En el caso de la indigencia, la diferencia es muy pequeña, con un máximo de 0,14 p.p. en 2003, por lo que las series apenas se diferencian.

\section{Estimación de los trimestres faltantes}

Una vez armonizadas las canastas básicas, recalibrados los quiebres muestrales de 2013 y 2016, y homogeneizados los métodos de imputación de ingresos, solo resta completar los trimestres en los que no se publicaron los microdatos de la encuesta, ya sea por no haberse hecho como en el tercer trimestre 2007 o bien por no haberse publicado debido a dudas en relación con su calidad, es decir, del tercer trimestre de 2015 al primero de 2016.

\subsection{Metodología de estimación}

Para realizar la estimación de los indicadores de pobreza e indigencia de los trimestres faltantes fue necesario calcular la evolución de los ingresos de las personas. Ante la falta de microdatos, esto se hizo a partir de fuentes alternativas de información. Para ello, en primer lugar, se dividió la población en ocho grupos. Luego se aplicó, a cada grupo, una determinada variación en sus ingresos y personas implicadas. Los grupos son: 1) personas mayores de 18 años y menores de

Figura 9. Tasa de pobreza, metodología nueva y EPH recalibrada, con y sin homogeneización del método de imputación de ingresos. Semestres móviles, 2003-2019

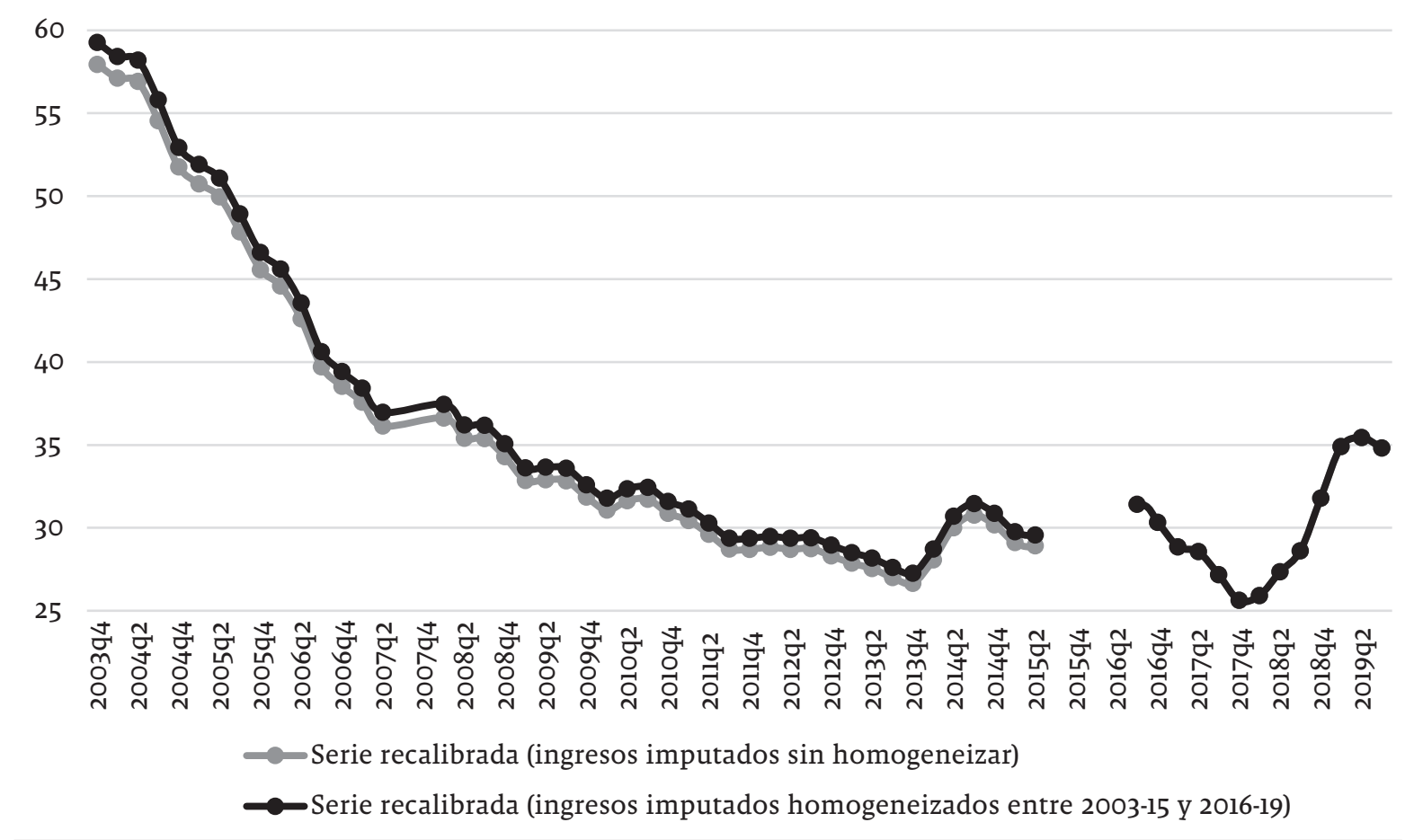

Fuente: elaboración propia basada en datos de EPH (INDEC, 2020d), IPC-San Luis (Gobierno de San Luis, 2020), IPC-CABA (Gobierno de la Ciudad de Buenos Aires, 2020a) e IPC-Córdoba (Gobierno de la provincia de Córdoba, 2020). 
65 que no trabajan (desocupados e inactivos); 2) asalariados formales privados; 3) asalariados públicos; 4) asalariados informales privados; 5) trabajadores no asalariados (cuentapropistas y empleadores mayormente); 6) jubilados; 7) personas mayores de 65 años que no cobran jubilación; 8) personas menores de 18 años.

La razón de esta separación en ocho grupos obedece a varios factores. En primer lugar, para los estratos 2, 3 y 6 contamos con datos provenientes de fuentes alternativas, como SIPA, Cuentas Nacionales del INDEC e INDEC, que los agregan respectivamente de ese modo. Para los otros cinco estratos, el criterio para la subdivisión fue el siguiente: a) diferenciar el remanente de ocupados, según se trate de asalariados no registrados y no asalariados, criterio que usa habitualmente el INDEC cuando, por ejemplo, efectúa la Cuenta de Generación del Ingreso. Para el resto de las personas que no trabajan, el criterio de separación fue etario: por un lado, las personas menores de edad; por otro, las personas adultas en edad laboral que no trabajan $y$, por último, las personas mayores de 65 años que no cobran jubilación.

Para la estimación de datos del tercer trimestre de 2007 el procedimiento fue más simple, dado que solo se trató de una observación faltante. Para ello, se interpolaron datos de ingresos para cada uno de estos ocho grupos entre el primer trimestre de 2007 y el primero de 2008. La elección de los trimestres impares se debe a que, en ellos, se computa el medio aguinaldo.

En cambio, la estimación de datos del segundo semestre de 2015 y el primer trimestre de 2016 fue más sofisticada, debido a que se trató de tres trimestres seguidos sin información, durante los cuales se produjo un quiebre en muchas variables relacionadas con la pobreza, como el ingreso y la inflación, entre otras. La tarea involucró tres variables principales. En primer lugar, se calculó la evolución de la cantidad de perceptores de ingresos, divididos entre ocupados y jubilados. Para ello, se estimaron los cambios en el peso relativo de cada uno de estos ocho grupos en el total de la población. En segundo lugar, se calculó qué ocurrió con los ingresos laborales y no laborales y, por lo tanto, con el ingreso de los hogares de cada uno de estos ocho estratos. Finalmente, se estimó la evolución de la distribución del ingreso.

En la Tabla 5, se muestra la metodología para estimar los primeros dos puntos en cada uno de los ocho grupos. En tres de estos ocho estratos, se tomó información proveniente de fuentes alternativas de muy elevada calidad al provenir de registros administrativos. La cantidad de asalariados formales privados y la mediana de su salario bruto se obtuvieron gracias a la información provista por el SIPA. Para la cantidad de asalariados públicos también se tomaron datos de ocupados del SIPA pero, para estimar su variación salarial, se consideró el índice de precios implícitos de "Administración Pública y Defensa", "Salud Pública" y "Enseñanza Pública" de las cuentas nacionales (ponderado por la participación de estas tres ramas en el empleo, según la EPH). Para estimar la cantidad de jubilados y sus ingresos se recurrió a la información provista por la ANSES. Respecto a los ingresos, se tomó la variación de la mediana, que es coincidente con la jubilación mínima. Como se ve en la Tabla 6, entre 2014 y 2016, estos tres estratos explicaron el 35,6\% de la población urbana argentina y el 70,1\% de los ingresos individuales.

Ante la ausencia de fuentes alternativas como los registros administrativos, se estimó la cantidad de personas en los otros cinco estratos y sus ingresos correspondientes interpolando geométricamente los datos de la EPH, recalibrada y con imputación de ingresos por hot-deck, previos y posteriores a los trimestres faltantes.

Pero esto no es tan inmediato, dado que el trimestre base sobre el cual se hace la proyección de ingresos es relevante: la distribución del ingreso varía e impacta sobre la pobreza e indigencia’. En efecto, la pobreza en el cuarto trimestre de 2015 puede estimarse aplicando variaciones interanuales de

7 Otra fuente de discrepancia en la evolución de la cantidad y los ingresos de los ocupados y jubilados es que estas variables difieren entre los registros administrativos y la EPH. La razón es que la EPH es una muestra y, por ende, está sujeta al error muestral. Además, existen problemas de captación de ingresos dado que, a ingresos crecientes, los encuestados tienden a subdeclarar sus ingresos. Asimismo, mientras que el SIPA mide el ingreso bruto, la EPH pregunta por el ingreso neto. 


\begin{tabular}{|c|c|c|c|}
\hline Grupo & $\begin{array}{l}\text { Método de estimación de } \\
\text { cantidades }\end{array}$ & Método de estimación de ingresos & Fuente \\
\hline $\begin{array}{l}\text { 1) mayores de } 18 \text { años y menores de } \\
65 \text { que no trabajan (desocupados e } \\
\text { inactivos) }\end{array}$ & $\begin{array}{l}\text { Interpolación geométrica entre } \\
\text { EPH 2014-2015 (recalibrada) y EPH } \\
\text { 2016-2017 }\end{array}$ & $\begin{array}{c}\text { Interpolación geométrica entre } \\
\text { EPH 2014-2015 (recalibrada) y EPH } \\
\text { 2016-2017 (con hot deck) }\end{array}$ & EPH \\
\hline 2) asalariados formales privados & Variaciones a partir del SIPA & Variaciones a partir del SIPA & SIPA \\
\hline 3) asalariados públicos & Variaciones a partir del SIPA & $\begin{array}{l}\text { Variaciones a partir del Índice de } \\
\text { Precios Implícitos de Adminis- } \\
\text { tración Pública, Salud Pública y } \\
\text { Enseñanza Pública de Cuentas } \\
\text { Nacionales del INDEC }\end{array}$ & $\begin{array}{l}\text { SIPA e } \\
\text { INDEC }\end{array}$ \\
\hline 4) asalariados informales privados & $\begin{array}{c}\text { Interpolación geométrica entre } \\
\text { EPH 2014-2015 (recalibrada) y EPH } \\
\text { 2016-2017 }\end{array}$ & $\begin{array}{c}\text { Interpolación geométrica entre } \\
\text { EPH 2014-2015 (recalibrada) y EPH } \\
\text { 2016-2017 (con hot deck) }\end{array}$ & EPH \\
\hline 5) trabajadores independientes & $\begin{array}{c}\text { Interpolación geométrica entre } \\
\text { EPH 2014-2015 (recalibrada) y EPH } \\
\text { 2016-2017 }\end{array}$ & $\begin{array}{l}\text { Interpolación geométrica entre } \\
\text { EPH 2014-2015 (recalibrada) y EPH } \\
\text { 2016-2017 (con hot deck) }\end{array}$ & EPH \\
\hline 6) jubilados & Variaciones a partir de ANSES & Variaciones a partir de ANSES & ANSES \\
\hline $\begin{array}{l}\text { 7) personas mayores de } 65 \text { años } \\
\text { que no cobran jubilación }\end{array}$ & $\begin{array}{c}\text { Interpolación geométrica entre } \\
\text { EPH 2014-2015 (recalibrada) y EPH } \\
\text { 2016-2017 }\end{array}$ & $\begin{array}{c}\text { Interpolación geométrica entre } \\
\text { EPH 2014-2015 (recalibrada) y EPH } \\
\text { 2016-2017 (con hot deck) }\end{array}$ & EPH \\
\hline 8) menores de 18 años & $\begin{array}{l}\text { Interpolación geométrica entre } \\
\text { EPH 2014-2015 (recalibrada) y EPH } \\
2016-2017\end{array}$ & $\begin{array}{c}\text { Interpolación geométrica entre } \\
\text { EPH 2014-2015 (recalibrada) y EPH } \\
\text { 2016-2017 (con hot deck) }\end{array}$ & EPH \\
\hline
\end{tabular}

Fuente: elaboración propia.

Tabla 6. Participación de estratos sociodemográficos en el total de las personas y en el total del ingreso individual, 2014-2016

\begin{tabular}{lcc}
\hline Estrato & $\begin{array}{c}\text { (\% del total de } \\
\text { personas) }\end{array}$ & $\begin{array}{c}\text { (\% del total del } \\
\text { ingreso individual) }\end{array}$ \\
\hline 1) mayores de 18 años y menores de 65 que no trabajan (desocupados e inactivos) & 15,6 & 2,0 \\
2) asalariados formales privados & 14,8 & 34,0 \\
3) asalariados públicos & 7,4 & 19,3 \\
4) asalariados informales privados & 9,9 & 11,5 \\
5) trabajadores independientes & 9,8 & 16,0 \\
6) jubilados & 13,4 & 16,8 \\
7) personas de más de 65 años que no cobran jubilación & 0,4 & 0,2 \\
8) menores de 18 años & 28,7 & 0,2 \\
Total & 100,0 & 100,0 \\
Total estratos 2, 3y 6 & 35,6 & 70,1 \\
Resto & 64,4 & 29,9 \\
\hline
\end{tabular}

Fuente: elaboración propia basada en EPH (INDEC, 2020d).

ingresos desde el mismo trimestre de 2014 (en lo que denominaremos una proyección interanual "hacia adelante"); desde el mismo trimestre de 2016 (proyección interanual "hacia atrás"); o desde los segundos trimestres de 2015 y 2016 (proyección semestral "hacia adelante" o "hacia atrás", respectivamente) ${ }^{8}$. La solución metodológica adoptada es calcular una cifra de pobreza e indigencia por cada 
uno de los posibles trimestres base mencionados y promediarlos.

Pero la distribución del ingreso es también relevante. Al utilizar la metodología detallada, la distribución estimada para cada uno de estos trimestres resulta básicamente de un promedio de las distribuciones de los trimestres base, lo que no necesariamente refleja la realidad. La única fuente alternativa trimestral para la dinámica de la distribución del ingreso es la ETOI. El problema es su cobertura geográfica, ya que solo se releva la CABA. Más allá de ello, la tendencia de la distribución del ingreso resultante de la ETOI y la EPH es similar entre el primer semestre de 2015 y el semestre móvil que va de abril a septiembre de 2016.

Para estimar la distribución del ingreso a través del índice de Gini en los trimestres faltantes, hemos realizado el promedio simple de dos estimaciones preliminares, una "hacia adelante" y otra "hacia atrás". En el primer caso, hemos tomado el Gini del segundo trimestre de 2015 y hemos calculado los trimestres faltantes, a partir de la variación del Gini reportada por la ETOI en los trimestres siguientes. En el segundo caso, hemos hecho lo mismo, pero partiendo desde el segundo trimestre de 2016 y yendo "hacia atrás". En la Figura 10, se muestra el Gini estimado en semestres móviles (Tabla C.3 y Figura C.I del Anexo C).

En este punto, tenemos para los trimestres faltantes: a) cantidad de personas en cada uno de los estratos; b) ingreso promedio de cada uno de dichos estratos; y c) un índice de Gini estimado que no necesariamente coincide con el resultante de a) y b). Para ello, se simuló un cambio en el Gini a partir de aplicar un impuesto proporcional al ingreso total familiar de todas las familias -cuya alícuota coincide con la variación deseada del indicador- y con lo recaudado se simuló un subsidio de suma fija e idéntica magnitud para todas las familias. Del mismo modo, si se simula una suba del Gini, se aplica un subsidio proporcional que es financiado por un impuesto de suma fija, idéntico para todas las familias (ver Anexo C -Tabla C.l, Tabla C.2, Tabla C.3 y Figura C.1-).

\subsection{Resultados estimados}

Como se observa en la Figura 1l, durante la segunda mitad de 2015 , la pobreza registró una tendencia descendente, alcanzando el 26,9\% de la población, similar al registrado en la segunda

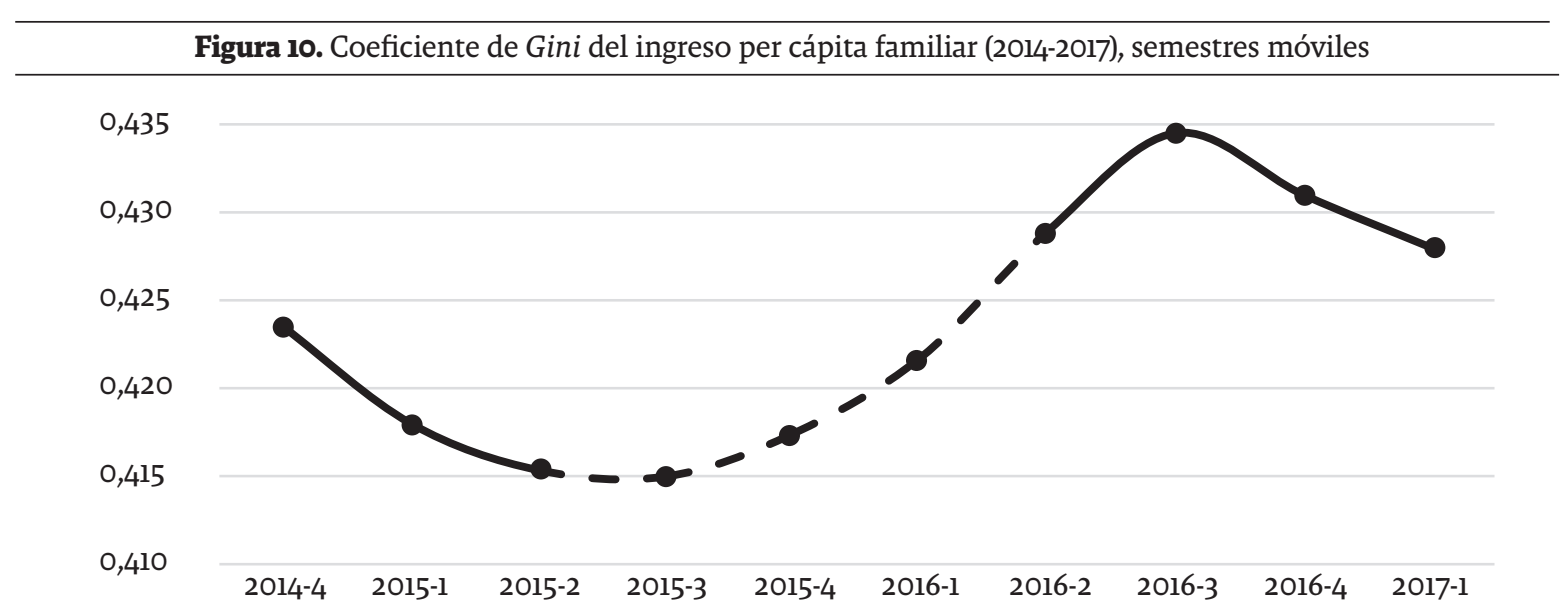

Nota: Las líneas rayadas muestran las estimaciones de los trimestres faltantes.

Fuente: elaboración propia basada en EPH (INDEC, 2020d) y ETOI-CABA (Gobierno de la Ciudad de Buenos Aires, 2020b).

8 Es problemático simular el resultado de trimestres pares a partir de impares, y viceversa, habida cuenta de la estacionalidad del medio aguinaldo. 


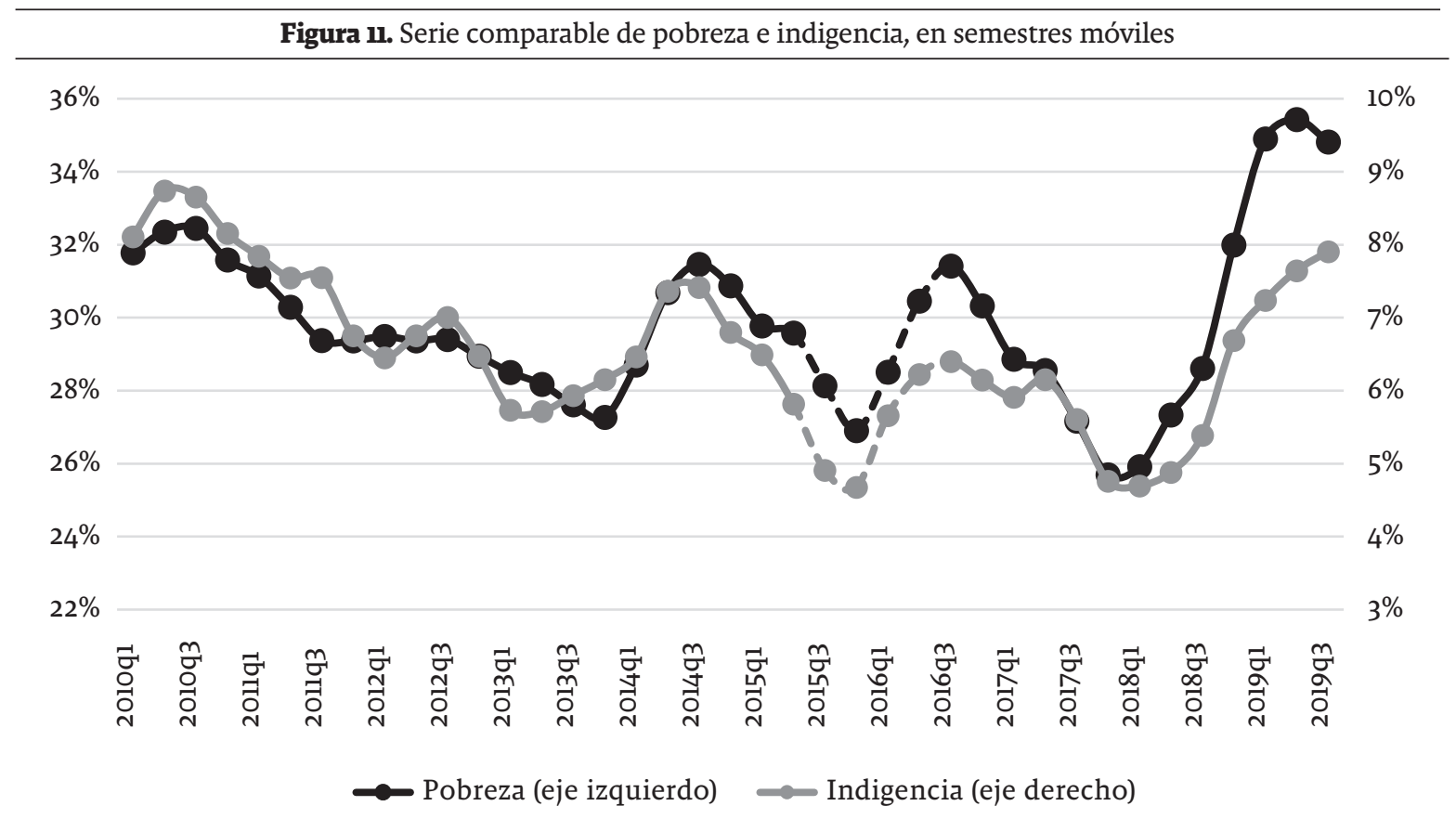

Nota: Las líneas rayadas muestran las estimaciones de los trimestres faltantes.

Fuente: elaboración propia basada en datos de EPH (INDEC, 2020d), SIPA (Ministerio de Trabajo, 2020), Censos Nacionales de Población y Vivienda (INDEC, 2020b), Cuentas Nacionales (INDEC, 2020c), ANSES (2020), ETOI-CABA (Gobierno de la Ciudad de Buenos Aires, 2020b), IPC-San Luis (Gobierno de San Luis, 2020), IPC-CABA (Gobierno de la Ciudad de Buenos Aires, 2020a) e IPC-Córdoba (Gobierno de la provincia de Córdoba, 2020).

mitad de 2013. Posteriormente, la tendencia se revirtió como resultado de la devaluación de finales de 2015 y su efecto sobre la inflación y el ingreso real. Así, la suba de la pobreza, entre la segunda mitad de 2015 y mediados de 2016, fue del orden de los 4,5 p.p., una magnitud similar a la registrada entre el segundo semestre de 2013 y mediados de 2014. La recuperación del poder adquisitivo y desaceleración inflacionaria posterior permitieron una baja de la pobreza, hasta alcanzar un mínimo del $25,7 \%$ en el segundo semestre de 2017. Un nuevo proceso devaluatorio y recesivo en 2018 cortó tal tendencia bajista.

Por su parte, la indigencia mostró una trayectoria similar. De acuerdo a nuestras estimaciones, a fines de 2015 rondó el 4,7\%, para trepar a alrededor de 1,7 p.p. en los primeros meses de 2016. En el semestre móvil comprendido entre octubre de 2017 y marzo de 2018, la indigencia regresó al mínimo de 4,7\%. Al igual que con la pobreza, la recesión y aceleración inflacionaria de 2018 implicaron un quiebre de tal recorrido descendente.

Por último, en la Figura 12 se exhiben las series completas y comparables de pobreza e indigencia (ver Tabla D.ı del Anexo D para los datos detallados por trimestre).

\section{Reflexiones finales}

Entre 2007 y 2015, el sistema estadístico argentino no contó con series confiables de pobreza e indigencia. Esto se debe, por un lado, a la subestimación de los datos de inflación que impactaron sobre la CBT y CBA. Por otro lado, durante el tercer trimestre de 2007, no se realizó la EPH por una huelga de encuestadores y, entre el tercer trimestre de 2015 y el primero de 2016, no se publicó la encuesta, en el marco del cambio de gobierno y la normalización del INDEC. 


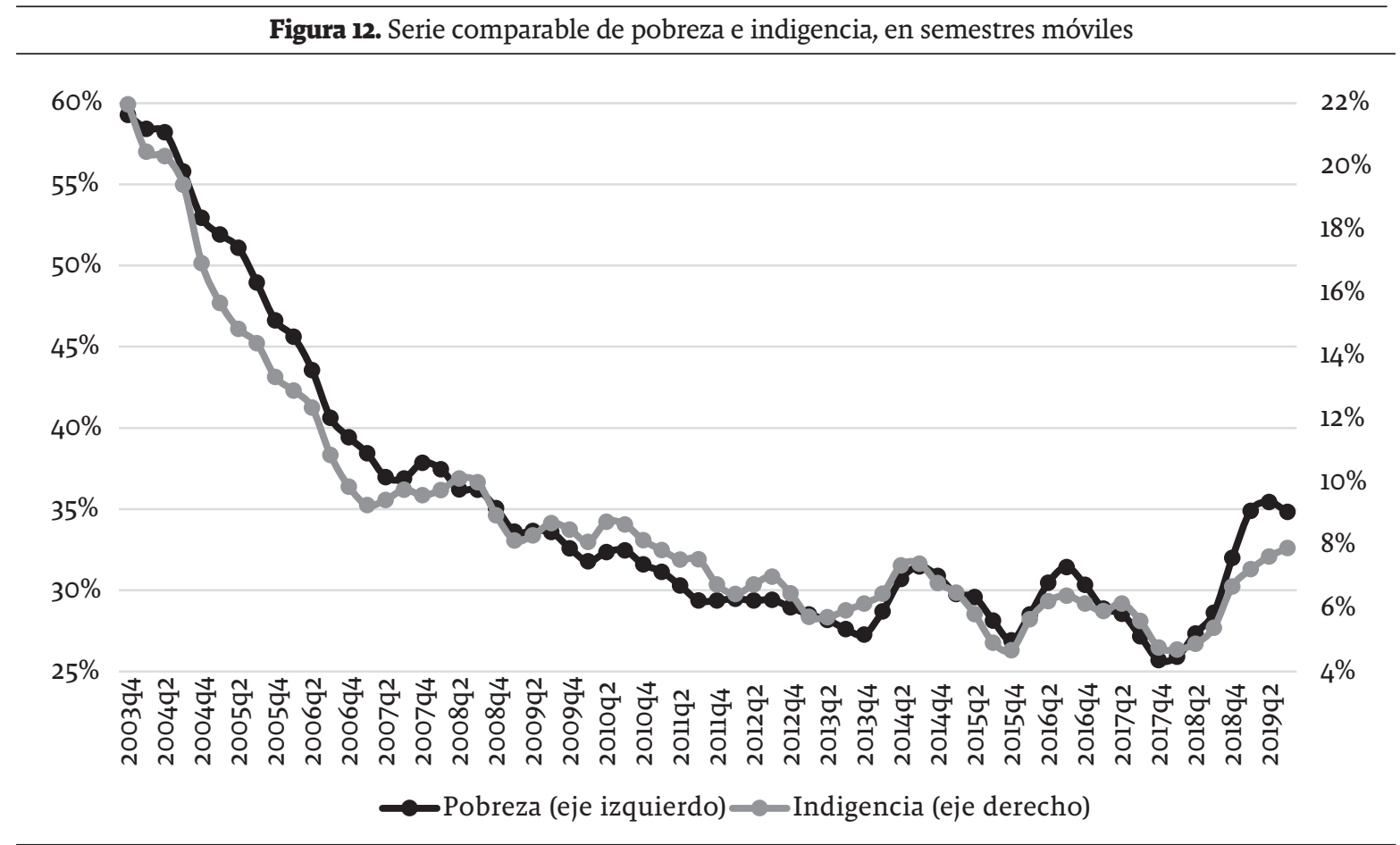

Fuente: elaboración propia basada en datos de EPH (INDEC, 2020d), SIPA (Ministerio de Trabajo, 2020), ANSES (2020), Censos Nacionales de Población y Vivienda (INDEC, 2020b), Cuentas Nacionales (INDEC, 2020c), ETOI-CABA (Gobierno de la Ciudad de Buenos Aires, 2020b), IPC-San Luis (Gobierno de San Luis, 2020), IPC-CABA (Gobierno de la Ciudad de Buenos Aires, 2020a) e IPC-Córdoba (Gobierno de la provincia de Córdoba, 2020).

Esto llevó a que, durante esos años, la discusión acerca de la pobreza e indigencia haya girado más en torno a sus valores reales que a las formas de reducirlas.

Como un intento de dejar atrás esta etapa sombría de las estadísticas argentinas y como forma de suplir algunas de las carencias que ha dejado, el objetivo del presente artículo ha sido crear una serie de pobreza e indigencia no solo metodológicamente homogénea, sino también completa. Asimismo, como la metodología empleada coincide con la utilizada actualmente por el INDEC, los datos que se publiquen en el futuro serán comparables con los calculados en este trabajo.

La construcción de esta serie de pobreza e indigencia, completa y metodológicamente homogénea, requirió de cuatro pasos: a) homogeneización de la metodología de las canastas básicas entre el período 2003-2015 y 2016-2018; b) recalibración de la EPH para mejorar la comparabilidad del período 2013-2016; c) armonización del método de imputación de ingresos; y d) estimación de la pobreza y la indigencia en los trimestres para los cuales no existen microdatos disponibles.

El análisis de los resultados permite arrojar varias conclusiones. En primer lugar, el cambio metodológico (paso "a") implicó una suba de alrededor de 10 p.p. en la incidencia de la pobreza; lo cual se explica, en primer término, por el cambio en el coeficiente de Engel y, en segundo término, por el contenido de la nueva canasta alimentaria. Las modificaciones en la tabla de adulto equivalente y en la regionalización de las canastas, por su parte, operaron como fuerzas parcialmente compensadoras. En el caso de la indigencia, el cambio metodológico aumentó la tasa 0,8 p.p. en promedio, lo cual se explica por la modificación de la canasta alimentaria (ya que el Engel no la afecta). 
En segundo lugar, la recalibración de la EPH (paso "b") permitió notar que la incidencia de la pobreza y la indigencia, entre el tercer trimestre de 2013 y el segundo trimestre de 2015, estaba ligeramente distorsionada producto de los cambios muestrales introducidos en cuatro ondas sucesivas a partir del tercer trimestre de 2013. Debido a estos cambios, la EPH original pasó a estar compuesta por un mayor porcentaje de hogares de nivel socioeconómico bajo, es decir, muchos miembros, con bajo nivel educativo del jefe del hogar $\mathrm{y}$ un alto porcentaje de niños, tendencia que se revirtió, a partir de 2016, con un nuevo cambio muestral. Hemos estimado que, en promedio, estas modificaciones introdujeron 1,2 p.p. más de pobres y 0,3 p.p. más de indigentes.

En tercer lugar, con la armonización del método de imputación de ingresos (paso "c") hemos podido observar que, en los últimos años, el método de "ponderadores específicos", característico del período 2016-2018, ha generado en promedio una tasa de pobreza 0,6 p.p. mayor que el método hotdeck, aunque ha tenido un impacto mínimo en la tasa de indigencia.

Por último, hemos calculado una tendencia de la pobreza y la indigencia en los trimestres faltantes. De acuerdo a nuestra estimación, en el segundo semestre de 2015 , la pobreza fue del $26,9 \%$ de la población, en tanto que la indigencia del 4,7\%. Nuestra serie estima un mínimo en la pobreza hacia finales de 2017 , levemente por debajo de los pisos de 2013 y 2015, revertido luego en 2018. En el caso de la indigencia, los pisos de la serie se ubicaron a fines de 2015, y entre fines de 2017 y principios de 2018. Todos estos datos muestran el estancamiento en las condiciones sociales de la Argentina desde 2011 y el deterioro que siguió a la crisis económica y cambiaria iniciada en abril de 2018. 


\section{Anexos}

\section{Anexo A}

Tabla A.l. Necesidades energéticas y unidades consumidoras, según edad y sexo

\begin{tabular}{|c|c|c|c|c|c|c|}
\hline \multirow[b]{2}{*}{ Sexo } & \multicolumn{3}{|c|}{ Nueva } & \multicolumn{3}{|c|}{ Vieja } \\
\hline & Edad & $\begin{array}{l}\text { Necesidad } \\
\text { Energética }\end{array}$ & $\begin{array}{c}\text { Unidades } \\
\text { consumidoras }\end{array}$ & Edad & $\begin{array}{l}\text { Necesidad } \\
\text { Energética }\end{array}$ & $\begin{array}{c}\text { Unidades } \\
\text { consumidoras }\end{array}$ \\
\hline \multirow[t]{11}{*}{ Ambos sexos } & 6-9 meses & 776 & 0,28 & $<1$ & 880 & 0,33 \\
\hline & 9-12 meses & 952 & 0,35 & & & \\
\hline & laño & 1030 & 0,37 & 1 año & 1170 & 0,43 \\
\hline & 2 años & 1277 & 0,46 & 2 años & 1360 & 0,50 \\
\hline & 3 años & 1409 & 0,51 & 3 años & 1500 & 0,56 \\
\hline & 4 años & 1518 & 0,55 & & & \\
\hline & 5 años & 1643 & 0,60 & 4-6 años & 1710 & 0,63 \\
\hline & 6 años & 1760 & 0,64 & & & \\
\hline & 7 años & 1813 & 0,66 & & & \\
\hline & 8 años & 1865 & 0,68 & 7-9 años & 1950 & 0,72 \\
\hline & 9 años & 1910 & 0,69 & & & \\
\hline \multirow[t]{8}{*}{ Varones } & 10 años & 2182 & 0,79 & & & \\
\hline & ll años & 2266 & 0,82 & 10-12 años & 2230 & 0,83 \\
\hline & 12 años & 2347 & 0,85 & & & \\
\hline & 13 años & 2472 & 0,90 & & & \\
\hline & 14 años & 2650 & 0,96 & 13-15 años & 2580 & 0,96 \\
\hline & 15 años & 2760 & 1,00 & & & \\
\hline & 16 años & 2828 & 1,03 & & & \\
\hline & 17 años & 2861 & 1,04 & 16-17 anos & 2840 & 1,05 \\
\hline \multirow[t]{8}{*}{ Mujeres } & 10 años & 1918 & 0,70 & & & \\
\hline & ll años & 1986 & 0,72 & 10-12 años & 1980 & 0,73 \\
\hline & 12 años & 2061 & 0,75 & & & \\
\hline & 13 años & 2089 & 0,76 & & & \\
\hline & 14 años & 2100 & 0,76 & 13-15 años & 2140 & 0,79 \\
\hline & 15 años & 2116 & 0,77 & & & \\
\hline & 16 años & $2 \mathrm{lll}$ & 0,77 & 16-17 วños & & \\
\hline & 17 años & 2124 & $0, \pi 7$ & 16-1/anos & 2140 & $0, / 9$ \\
\hline \multirow[t]{5}{*}{ Varones } & 18-29 años & 2826 & 1,03 & 18-29 años & 2860 & 1,06 \\
\hline & 30-45 años & 2750 & 1,00 & & & \\
\hline & 46-60 años & 2760 & 1,00 & 30-59 anos & 2700 & 1 \\
\hline & 61-75 años & 2288 & 0,83 & más de 60 años & ה20 & 28 \\
\hline & más de 75 & 2050 & 0,75 & mas de ou anos & 2210 & 0,02 \\
\hline \multirow[t]{5}{*}{ Mujeres } & 18-29 años & 2106 & $0, \pi 7$ & $18-29$ & 2000 & 0,74 \\
\hline & 30-45 años & 2111 & 0,77 & & & \\
\hline & 46-60 años & 2090 & 0,76 & 30-59 años & 2000 & 0,74 \\
\hline & 61-75 años & 1860 & 0,68 & & & \\
\hline & más de 75 & 1750 & 0,64 & mas de 60 anos & 1730 & 0,64 \\
\hline
\end{tabular}

Fuente: elaboración propia basada en INDEC (2004).

Tabla A.2. Composición de la Canasta Básica Alimentaria por adulto equivalente

\begin{tabular}{lc|c|c|c}
\hline & Productos & $\begin{array}{c}\text { Nueva } \\
\text { (gramos) }\end{array}$ & $\begin{array}{c}\text { Vieja } \\
\text { (gramos) }\end{array}$ & $\begin{array}{c}\text { Diferencia Nueva - } \\
\text { Vieja (gramos) }\end{array}$ \\
\hline Pan & 6750 & 6060 & 690 \\
Galletitas saladas & 420 & 420 & 0 \\
Galletitas dulces & 210 & 720 & -510 \\
Arroz & 1200 & 630 & 570 \\
Harina de trigo & & 1080 & 1020 & 60
\end{tabular}






\section{Anexo B}

Tabla B.1. Canasta Básica Alimentaria por adulto equivalente

\begin{tabular}{ccccccc}
\hline Trimestre & GBA & Cuyo & NEA & NOA & Pampeana & Patagónica \\
\hline $3 q 2003$ & $\$ 112,22$ & $\$ 100,65$ & $\$ 101,64$ & $\$ 98,84$ & $\$ 112,26$ & $\$ 115,37$ \\
$4 q 2003$ & $\$ 115,43$ & $\$ 103,52$ & $\$ 104,53$ & $\$ 101,66$ & $\$ 115,46$ & $\$ 118,66$ \\
$1 q 2004$ & $\$ 116,48$ & $\$ 104,46$ & $\$ 105,49$ & $\$ 102,59$ & $\$ 116,51$ & $\$ 119,74$ \\
$2 q 2004$ & $\$ 117,24$ & $\$ 105,14$ & $\$ 106,17$ & $\$ 103,25$ & $\$ 117,27$ & $\$ 120,52$ \\
$3 q 2004$ & $\$ 118,16$ & $\$ 105,97$ & $\$ 107,01$ & $\$ 104,07$ & $\$ 118,19$ & $\$ 121,47$ \\
$4 q 2004$ & $\$ 118,94$ & $\$ 106,67$ & $\$ 107,72$ & $\$ 104,75$ & $\$ 118,97$ & $\$ 122,27$ \\
$1 q 2005$ & $\$ 122,61$ & $\$ 109,96$ & $\$ 111,04$ & $\$ 107,99$ & $\$ 122,65$ & $\$ 126,05$ \\
$2 q 2005$ & $\$ 125,53$ & $\$ 112,58$ & $\$ 113,69$ & $\$ 110,56$ & $\$ 125,57$ & $\$ 129,05$ \\
$3 q 2005$ & $\$ 129,46$ & $\$ 116,10$ & $\$ 117,24$ & $\$ 114,02$ & $\$ 129,49$ & $\$ 133,08$ \\
$4 q 2005$ & $\$ 135,54$ & $\$ 121,55$ & $\$ 122,75$ & $\$ 119,37$ & $\$ 135,57$ & $\$ 139,33$ \\
$1 q 2006$ & $\$ 139,64$ & $\$ 125,23$ & $\$ 126,46$ & $\$ 122,99$ & $\$ 139,68$ & $\$ 143,55$ \\
$2 q 2006$ & $\$ 139,35$ & $\$ 124,98$ & $\$ 126,20$ & $\$ 122,73$ & $\$ 139,39$ & $\$ 143,26$ \\
$3 q 2006$ & $\$ 138,89$ & $\$ 124,56$ & $\$ 125,78$ & $\$ 122,32$ & $\$ 138,93$ & $\$ 142,78$ \\
$4 q 2006$ & $\$ 145,29$ & $\$ 130,30$ & $\$ 131,58$ & $\$ 127,96$ & $\$ 145,33$ & $\$ 149,36$ \\
$1 q 2007$ & $\$ 153,50$ & $\$ 137,67$ & $\$ 139,02$ & $\$ 135,20$ & $\$ 153,55$ & $\$ 157,80$ \\
$2 q 2007$ & $\$ 168,41$ & $\$ 151,03$ & $\$ 152,52$ & $\$ 148,32$ & $\$ 168,45$ & $\$ 173,12$ \\
$3 q 2007$ & $\$ 190,83$ & $\$ 171,14$ & $\$ 172,82$ & $\$ 168,07$ & $\$ 190,88$ & $\$ 196,17$ \\
$4 q 2007$ & $\$ 197,17$ & $\$ 176,83$ & $\$ 178,57$ & $\$ 173,66$ & $\$ 197,23$ & $\$ 202,70$ \\
$1 q 2008$ & $\$ 213,37$ & $\$ 191,36$ & $\$ 193,24$ & $\$ 187,92$ & $\$ 213,43$ & $\$ 219,35$ \\
$2 q 2008$ & $\$ 234,17$ & $\$ 210,02$ & $\$ 212,08$ & $\$ 206,25$ & $\$ 234,24$ & $\$ 240,73$ \\
$3 q 2008$ & $\$ 238,06$ & $\$ 213,50$ & $\$ 215,59$ & $\$ 209,67$ & $\$ 238,13$ & $\$ 244,73$
\end{tabular}


Pobreza e indigencia en Argentina: construcción de una serie completa y metodológicamente homogénea

\begin{tabular}{|c|c|c|c|c|c|c|}
\hline Trimestre & GBA & Cuyo & NEA & NOA & Pampeana & Patagónica \\
\hline $4 q 2008$ & $\$ 239,68$ & $\$ 214,95$ & $\$ 217,06$ & $\$ 211,10$ & $\$ 239,75$ & $\$ 246,39$ \\
\hline $1 q 2009$ & $\$ 243,14$ & $\$ 218,06$ & $\$ 220,20$ & $\$ 214,15$ & $\$ 243,21$ & $\$ 249,96$ \\
\hline $2 q 2009$ & $\$ 251,60$ & $\$ 225,65$ & $\$ 227,86$ & $\$ 221,60$ & $\$ 251,67$ & $\$ 258,65$ \\
\hline $3 q 2009$ & $\$ 258,61$ & $\$ 231,93$ & $\$ 234,21$ & $\$ 227,77$ & $\$ 258,68$ & $\$ 265,85$ \\
\hline $4 q 2009$ & $\$ 274,25$ & $\$ 245,95$ & $\$ 248,37$ & $\$ 241,54$ & $\$ 274,32$ & $\$ 281,93$ \\
\hline $1 q 2010$ & $\$ 321,49$ & $\$ 288,32$ & $\$ 291,15$ & $\$ 283,15$ & $\$ 321,58$ & $\$ 330,50$ \\
\hline $2 q 2010$ & $\$ 346,67$ & $\$ 310,91$ & $\$ 313,96$ & $\$ 305,33$ & $\$ 346,77$ & $\$ 356,38$ \\
\hline $3 q 2010$ & $\$ 357,41$ & $\$ 320,54$ & $\$ 323,68$ & $\$ 314,79$ & $\$ 357,51$ & $\$ 367,42$ \\
\hline 492010 & $\$ 392,73$ & $\$ 352,21$ & $\$ 355,67$ & $\$ 345,89$ & $\$ 392,84$ & $\$ 403,73$ \\
\hline 1q2011 & $\$ 410,62$ & $\$ 368,26$ & $\$ 371,87$ & $\$ 361,65$ & $\$ 410,74$ & $\$ 422,12$ \\
\hline 2q2011 & $\$ 438,74$ & $\$ 393,48$ & $\$ 397,34$ & $\$ 386,42$ & $\$ 438,87$ & $\$ 451,03$ \\
\hline $3 q 2011$ & $\$ 463,22$ & $\$ 415,43$ & $\$ 419,51$ & $\$ 407,98$ & $\$ 463,35$ & $\$ 476,20$ \\
\hline $4 q 2011$ & $\$ 479,90$ & $\$ 430,40$ & $\$ 434,62$ & $\$ 422,67$ & $\$ 480,04$ & $\$ 493,35$ \\
\hline 192012 & $\$ 504,54$ & $\$ 452,49$ & $\$ 456,93$ & $\$ 444,37$ & $\$ 504,68$ & $\$ 518,67$ \\
\hline $2 q 2012$ & $\$ 544,20$ & $\$ 488,06$ & $\$ 492,85$ & $\$ 479,30$ & $\$ 544,36$ & $\$ 559,45$ \\
\hline $3 q 2012$ & $\$ 574,35$ & $\$ 515,10$ & $\$ 520,15$ & $\$ 505,85$ & $\$ 574,51$ & $\$ 590,44$ \\
\hline $4 q 2012$ & $\$ 602,29$ & $\$ 540,16$ & $\$ 545,46$ & $\$ 530,47$ & $\$ 602,47$ & $\$ 619,17$ \\
\hline $1 q 2013$ & $\$ 631,06$ & $\$ 565,96$ & $\$ 571,51$ & $\$ 555,80$ & $\$ 631,24$ & $\$ 648,74$ \\
\hline $2 q 2013$ & $\$ 661,89$ & $\$ 593,61$ & $\$ 599,44$ & $\$ 582,96$ & $\$ 662,08$ & $\$ 680,44$ \\
\hline $3 q 2013$ & $\$ 714,00$ & $\$ 640,35$ & $\$ 646,63$ & $\$ 628,85$ & $\$ 714,21$ & $\$ 734,01$ \\
\hline $4 q 2013$ & $\$ 783,95$ & $\$ 703,08$ & $\$ 709,98$ & $\$ 690,46$ & $\$ 784,17$ & $\$ 805,91$ \\
\hline 192014 & $\$ 888,12$ & $\$ 796,50$ & $\$ 804,32$ & $\$ 782,20$ & $\$ 888,37$ & $\$ 913,00$ \\
\hline $2 q 2014$ & $\$ 958,23$ & $\$ 859,37$ & $\$ 867,81$ & $\$ 843,95$ & $\$ 958,50$ & $\$ 985,07$ \\
\hline $3 q 2014$ & $\$ 1005,72$ & $\$ 901,97$ & $\$ 910,82$ & $\$ 885,78$ & $\$ 1006,00$ & $\$ 1033,89$ \\
\hline 492014 & $\$ 1054,32$ & $\$ 945,55$ & $\$ 954,83$ & $\$ 928,58$ & $\$ 1054,62$ & $\$ 1083,85$ \\
\hline 192015 & $\$ 1100,64$ & $\$ 987,10$ & $\$ 996,78$ & $\$ 969,38$ & $\$ 1100,95$ & $\$ 1131,47$ \\
\hline $2 q 2015$ & $\$ 1144,84$ & $\$ 1026,73$ & $\$ 1036,81$ & $\$ 1008,30$ & $\$ 1145,16$ & $\$ 1176,91$ \\
\hline $3 q 2015$ & $\$ 1200,32$ & $\$ 1076,50$ & $\$ 1087,06$ & $\$ 1057,18$ & $\$ 1200,67$ & $\$ 1233,95$ \\
\hline $4 q 2015$ & $\$ 1284,12$ & $\$ 1151,65$ & $\$ 1162,95$ & $\$ 1130,98$ & $\$ 1284,49$ & $\$ 1320,10$ \\
\hline $1 q 2016$ & $\$ 1453,50$ & $\$ 1303,56$ & $\$ 1316,35$ & $\$ 1280,16$ & $\$ 1453,91$ & $\$ 1494,22$ \\
\hline $2 q 2016$ & $\$ 1563,40$ & $\$ 1400,57$ & $\$ 1407,84$ & $\$ 1372,35$ & $\$ 1564,01$ & $\$ 1607,56$ \\
\hline 392016 & $\$ 1684,25$ & $\$ 1508,81$ & $\$ 1512,93$ & $\$ 1472,08$ & $\$ 1676,16$ & $\$ 1735,14$ \\
\hline $4 q 2016$ & $\$ 1756,20$ & $\$ 1570,30$ & $\$ 1568,09$ & $\$ 1525,45$ & $\$ 1746,40$ & $\$ 1813,35$ \\
\hline $1 q 2017$ & $\$ 1829,00$ & $\$ 1634,68$ & $\$ 1632,39$ & $\$ 1587,99$ & $\$ 1818,00$ & $\$ 1887,69$ \\
\hline $2 q 2017$ & $\$ 1936,38$ & $\$ 1731,19$ & $\$ 1680,61$ & $\$ 1727,42$ & $\$ 1921,31$ & $\$ 1994,25$ \\
\hline $3 q 2017$ & $\$ 2018,67$ & $\$ 1804,76$ & $\$ 1752,04$ & $\$ 1800,83$ & $\$ 2002,97$ & $\$ 2079,00$ \\
\hline 492017 & $\$ 2118,46$ & $\$ 1893,97$ & $\$ 1838,64$ & $\$ 1889,85$ & $\$ 2101,98$ & $\$ 2181,77$ \\
\hline $1 q 2018$ & $\$ 2251,00$ & $\$ 2011,24$ & $\$ 2008,10$ & $\$ 1958,89$ & $\$ 2242,62$ & $\$ 2326,38$ \\
\hline $2 q 2018$ & $\$ 2421,40$ & $\$ 2163,49$ & $\$ 2160,11$ & $\$ 2107,18$ & $\$ 2412,39$ & $\$ 2502,40$ \\
\hline $3 q 2018$ & $\$ 2753,33$ & $\$ 2467,00$ & $\$ 2461,67$ & $\$ 2403,67$ & $\$ 2467,00$ & $\$ 2730,67$ \\
\hline 492018 & $\$ 3242,33$ & $\$ 2899,33$ & $\$ 2886,67$ & $\$ 2812,33$ & $\$ 3212,67$ & $\$ 3341,00$ \\
\hline $1 q 2019$ & $\$ 3595,93$ & $\$ 3214,93$ & $\$ 3208,57$ & $\$ 3131,59$ & $\$ 3578,48$ & $\$ 3717,93$ \\
\hline $2 q 2019$ & $\$ 3920,31$ & $\$ 3504,93$ & $\$ 3498,00$ & $\$ 3414,07$ & $\$ 3901,28$ & $\$ 4053,31$ \\
\hline $3 q 2019^{*}$ & $\$ 4309,17$ & $\$ 3852,58$ & $\$ 3844,97$ & $\$ 3752,72$ & $\$ 4288,25$ & $\$ 4455,36$ \\
\hline
\end{tabular}

Nota: Salvo GBA, los datos de las canastas regionales del $3 q 2019$ son preliminares, ya que al momento de la escritura de este artículo INDEC no los publicó oficialmente.

Fuente: elaboración propia basada en INDEC (2020a), IPC-San Luis (Gobierno de San Luis, 2020), IPC-CABA (Gobierno de la Ciudad de Buenos Aires, 2020a) e IPC-Córdoba (Gobierno de la provincia de Córdoba, 2020). 


\begin{tabular}{|c|c|c|c|c|c|c|}
\hline Trimestre & GBA & Cuyo & NEA & NOA & Pampeana & Patagónica \\
\hline $3 q 2003$ & $\$ 300,59$ & $\$ 288,36$ & $\$ 253,27$ & $\$ 244,00$ & $\$ 300,68$ & $\$ 353,40$ \\
\hline $4 q 2003$ & $\$ 305,89$ & $\$ 293,44$ & $\$ 257,74$ & $\$ 248,31$ & $\$ 305,98$ & $\$ 359,63$ \\
\hline 192004 & $\$ 309,16$ & $\$ 296,58$ & $\$ 260,49$ & $\$ 250,96$ & $\$ 309,25$ & $\$ 363,47$ \\
\hline $2 q 2004$ & $\$ 311,18$ & $\$ 298,51$ & $\$ 262,19$ & $\$ 252,59$ & $\$ 311,27$ & $\$ 365,84$ \\
\hline 392004 & $\$ 314,56$ & $\$ 301,76$ & $\$ 265,04$ & $\$ 255,34$ & $\$ 314,65$ & $\$ 369,82$ \\
\hline 492004 & $\$ 317,61$ & $\$ 304,69$ & $\$ 267,61$ & $\$ 257,82$ & $\$ 317,70$ & $\$ 373,41$ \\
\hline $1 q 2005$ & $\$ 327,37$ & $\$ 314,05$ & $\$ 275,83$ & $\$ 265,74$ & $\$ 327,47$ & $\$ 384,88$ \\
\hline $2 q 2005$ & $\$ 333,70$ & $\$ 320,12$ & $\$ 281,16$ & $\$ 270,88$ & $\$ 333,79$ & $\$ 392,32$ \\
\hline $3 q 2005$ & $\$ 341,99$ & $\$ 328,07$ & $\$ 288,15$ & $\$ 277,61$ & $\$ 342,09$ & $\$ 402,07$ \\
\hline 492005 & $\$ 354,79$ & $\$ 340,35$ & $\$ 298,94$ & $\$ 288,00$ & $\$ 354,89$ & $\$ 417,12$ \\
\hline $1 q 2006$ & $\$ 365,59$ & $\$ 350,71$ & $\$ 308,04$ & $\$ 296,76$ & $\$ 365,69$ & $\$ 429,81$ \\
\hline $2 q 2006$ & $\$ 367,43$ & $\$ 352,57$ & $\$ 309,48$ & $\$ 298,14$ & $\$ 367,53$ & $\$ 432,21$ \\
\hline $3 q 2006$ & $\$ 368,98$ & $\$ 354,17$ & $\$ 310,68$ & $\$ 299,29$ & $\$ 369,08$ & $\$ 434,29$ \\
\hline $4 q 2006$ & $\$ 382,48$ & $\$ 367,00$ & $\$ 322,19$ & $\$ 310,39$ & $\$ 382,59$ & $\$ 449,86$ \\
\hline $1 q 2007$ & $\$ 397,61$ & $\$ 381,26$ & $\$ 335,18$ & $\$ 322,94$ & $\$ 397,72$ & $\$ 467,07$ \\
\hline $2 q 2007$ & $\$ 418,70$ & $\$ 400,80$ & $\$ 353,65$ & $\$ 340,82$ & $\$ 418,81$ & $\$ 490,22$ \\
\hline $3 q 2007$ & $\$ 455,82$ & $\$ 435,58$ & $\$ 385,77$ & $\$ 371,88$ & $\$ 455,95$ & $\$ 531,90$ \\
\hline 492007 & $\$ 487,69$ & $\$ 466,74$ & $\$ 412,03$ & $\$ 397,09$ & $\$ 487,83$ & $\$ 570,76$ \\
\hline $1 q 2008$ & $\$ 514,84$ & $\$ 492,20$ & $\$ 435,50$ & $\$ 419,79$ & $\$ 514,99$ & $\$ 601,29$ \\
\hline $2 q 2008$ & $\$ 552,81$ & $\$ 527,98$ & $\$ 468,13$ & $\$ 451,31$ & $\$ 552,97$ & $\$ 644,42$ \\
\hline $3 q 2008$ & $\$ 579,81$ & $\$ 554,53$ & $\$ 490,22$ & $\$ 472,51$ & $\$ 579,97$ & $\$ 677,70$ \\
\hline 492008 & $\$ 592,36$ & $\$ 566,89$ & $\$ 500,48$ & $\$ 482,34$ & $\$ 592,53$ & $\$ 693,21$ \\
\hline $1 q 2009$ & $\$ 610,23$ & $\$ 584,37$ & $\$ 515,19$ & $\$ 496,47$ & $\$ 610,40$ & $\$ 715,02$ \\
\hline $2 q 2009$ & $\$ 629,37$ & $\$ 602,62$ & $\$ 531,44$ & $\$ 512,14$ & $\$ 629,55$ & $\$ 737,25$ \\
\hline $3 q 2009$ & $\$ 654,10$ & $\$ 626,59$ & $\$ 552,02$ & $\$ 531,94$ & $\$ 654,28$ & $\$ 766,90$ \\
\hline 492009 & $\$ 684,30$ & $\$ 655,14$ & $\$ 577,88$ & $\$ 556,91$ & $\$ 684,49$ & $\$ 801,43$ \\
\hline $1 q 2010$ & $\$ 730,85$ & $\$ 696,82$ & $\$ 620,11$ & $\$ 597,99$ & $\$ 731,06$ & $\$ 849,12$ \\
\hline $2 q 2010$ & $\$ 780,21$ & $\$ 743,54$ & $\$ 662,35$ & $\$ 638,76$ & $\$ 780,43$ & $\$ 905,64$ \\
\hline $3 q 2010$ & $\$ 821,37$ & $\$ 783,52$ & $\$ 696,52$ & $\$ 671,61$ & $\$ 821,60$ & $\$ 955,21$ \\
\hline $4 q 2010$ & $\$ 866,16$ & $\$ 824,65$ & $\$ 736,12$ & $\$ 710,01$ & $\$ 866,41$ & $\$ 1003,53$ \\
\hline $1 q 2011$ & \$ 916,86 & $\$ 873,43$ & $\$ 778,69$ & $\$ 751,00$ & $\$ 917,12$ & $\$ 1063,49$ \\
\hline 2q2011 & $\$ 987,30$ & $\$ 940,89$ & $\$ 838,16$ & $\$ 808,31$ & $\$ 987,58$ & $\$ 1146,01$ \\
\hline $3 q 2011$ & $\$ 1055,57$ & $\$ 1006,54$ & $\$ 895,52$ & $\$ 863,55$ & $\$ 1055,87$ & $\$ 1226,66$ \\
\hline $4 q 2011$ & \$ 1111,86 & $\$ 1061,02$ & $\$ 942,46$ & $\$ 908,70$ & $\$ 1112,17$ & $\$ 1293,98$ \\
\hline $1 q 2012$ & $\$ 1165,02$ & $\$ 1111,58$ & $\$ 987,69$ & $\$ 952,34$ & $\$ 1165,35$ & $\$ 1355,44$ \\
\hline $2 \mathrm{q} 2012$ & $\$ 1238,57$ & $\$ 1180,97$ & $\$ 1050,84$ & $\$ 1013,34$ & $\$ 1238,92$ & $\$ 1439,15$ \\
\hline $3 q 2012$ & $\$ 1305,30$ & $\$ 1244,51$ & $\$ 1107,54$ & $\$ 1068,02$ & $\$ 1305,67$ & $\$ 1516,49$ \\
\hline $4 q 2012$ & $\$ 1374,80$ & $\$ 1311,04$ & $\$ 1166,24$ & $\$ 1124,59$ & $\$ 1375,19$ & $\$ 1597,86$ \\
\hline $1 q 2013$ & $\$ 1448,64$ & $\$ 1381,82$ & $\$ 1228,51$ & $\$ 1184,59$ & $\$ 1449,05$ & $\$ 1684,54$ \\
\hline $2 \mathrm{q} 2013$ & $\$ 1524,25$ & $\$ 1454,15$ & $\$ 1292,42$ & $\$ 1246,19$ & $\$ 1524,68$ & $\$ 1772,96$ \\
\hline 392013 & $\$ 1615,60$ & $\$ 1540,04$ & $\$ 1371,14$ & $\$ 1322,26$ & $\$ 1616,05$ & $\$ 1876,24$ \\
\hline $4 q 2013$ & $\$ 1743,10$ & $\$ 1660,21$ & $\$ 1480,75$ & $\$ 1428,14$ & $\$ 1743,60$ & $\$ 2021,08$ \\
\hline $1 q 2014$ & $\$ 1951,31$ & $\$ 1857,46$ & $\$ 1658,69$ & $\$ 1599,90$ & $\$ 1951,87$ & $\$ 2259,97$ \\
\hline $2 q 2014$ & $\$ 2124,85$ & $\$ 2023,54$ & $\$ 1805,30$ & $\$ 1741,19$ & $\$ 2125,45$ & $\$ 2463,08$ \\
\hline 392014 & $\$ 2265,92$ & $\$ 2159,52$ & $\$ 1923,51$ & $\$ 1854,99$ & $\$ 2266,57$ & $\$ 2630,46$ \\
\hline 492014 & $\$ 2407,03$ & $\$ 2295,42$ & $\$ 2041,87$ & $\$ 1968,94$ & $\$ 2407,72$ & $\$ 2797,62$ \\
\hline $1 q 2015$ & $\$ 2539,24$ & $\$ 2422,67$ & $\$ 2152,84$ & $\$ 2075,80$ & $\$ 2539,96$ & $\$ 2954,06$ \\
\hline $2 q 2015$ & $\$ 2687,45$ & $\$ 2566,10$ & $\$ 2276,45$ & $\$ 2194,72$ & $\$ 2688,22$ & $\$ 3131,27$ \\
\hline $3 q 2015$ & $\$ 2838,09$ & $\$ 2710,81$ & $\$ 2403,16$ & $\$ 2316,77$ & $\$ 2838,89$ & $\$ 3308,85$ \\
\hline $4 q 2015$ & $\$ 3034,81$ & $\$ 2898,65$ & $\$ 2569,79$ & $\$ 2477,42$ & $\$ 3035,67$ & $\$ 3538,06$ \\
\hline $1 q 2016$ & $\$ 3393,30$ & $\$ 3239,27$ & $\$ 2875,16$ & $\$ 2772,04$ & $\$ 3394,26$ & $\$ 3951,77$ \\
\hline $2 q 2016$ & $\$ 3809,80$ & $\$ 3637,10$ & $\$ 3214,92$ & $\$ 3106,46$ & $\$ 3811,30$ & $\$ 4447,91$ \\
\hline $3 q 2016$ & $\$ 4053,19$ & $\$ 3872,37$ & $\$ 3413,95$ & $\$ 3292,33$ & $\$ 4033,72$ & $\$ 4742,32$ \\
\hline $4 q 2016$ & $\$ 4232,45$ & $\$ 4030,41$ & $\$ 3538,65$ & $\$ 3411,90$ & $\$ 4208,81$ & $\$ 4962,51$ \\
\hline $1 q 2017$ & $\$ 4432,32$ & $\$ 4221,04$ & $\$ 3704,06$ & $\$ 3571,25$ & $\$ 4406,78$ & $\$ 5198,46$ \\
\hline $2 q 2017$ & $\$ 4744,12$ & $\$ 4512,69$ & $\$ 3820,66$ & $\$ 3961,60$ & $\$ 4700,88$ & $\$ 5550,71$ \\
\hline
\end{tabular}


Pobreza e indigencia en Argentina: construcción de una serie completa y metodológicamente homogénea

\begin{tabular}{ccccccc}
\hline \multicolumn{7}{c}{ Tabla B.2. Canasta Básica Total por adulto equivalente } \\
\hline Trimestre & GBA & Cuyo & NEA & NOA & Pampeana & Patagónica \\
\hline $3 q 2017$ & $\$ 4931,99$ & $\$ 4691,39$ & $\$ 3971,95$ & $\$ 4118,48$ & $\$ 4887,03$ & $\$ 5770,52$ \\
$4 q 2017$ & $\$ 5219,01$ & $\$ 4964,41$ & $\$ 4203,10$ & $\$ 4358,15$ & $\$ 5171,44$ & $\$ 6106,34$ \\
$1 q 2018$ & $\$ 5649,95$ & $\$ 5389,02$ & $\$ 4718,07$ & $\$ 4562,10$ & $\$ 5626,68$ & $\$ 6628,42$ \\
$2 q 2018$ & $\$ 6115,79$ & $\$ 5833,31$ & $\$ 5107,07$ & $\$ 4938,24$ & $\$ 6090,60$ & $\$ 7174,9$ \\
$3 q 2018$ & $\$ 6856,65$ & $\$ 6537,66$ & $\$ 5735,76$ & $\$ 5552,90$ & $\$ 6799,42$ & $\$ 8017,66$ \\
$4 q 2018$ & $\$ 8084,25$ & $\$ 7692,51$ & $\$ 6734,93$ & $\$ 6505,58$ & $\$ 8009,99$ & $\$ 9444,39$ \\
$1 q 2019$ & $\$ 8928,19$ & $\$ 8490,97$ & $\$ 7458,62$ & $\$ 7217,79$ & $\$ 8884,92$ & $\$ 10469,6$ \\
2q2019 & $\$ 9814,44$ & $\$ 9333,82$ & $\$ 8199,00$ & $\$ 7934,26$ & $\$ 9766,88$ & $\$ 11508,86$ \\
$3 q 2019 *$ & $\$ 10758,62$ & $\$ 10231,77$ & $\$ 8987,77$ & $\$ 8697,56$ & $\$ 10706,48$ & $\$ 12616,05$ \\
\hline
\end{tabular}

Nota: Salvo GBA, los datos de las canastas regionales del 3q2019 son preliminares, ya que al momento de la escritura de este artículo INDEC no los publicó oficialmente.

Fuente: elaboración propia basada en INDEC (2020a), IPC-San Luis (Gobierno de San Luis, 2020), IPC-CABA (Gobierno de la Ciudad de Buenos Aires, 2020a) e IPC-Córdoba (Gobierno de la provincia de Córdoba, 2020).

\section{Anexo C}

Tabla C.1. Estimación de cantidad de personas por estrato socio-ocupacional, simulaciones 2015-2016

\begin{tabular}{cccccccccc}
\hline Período & Estrato 1 & Estrato 2 & Estrato 3 & Estrato 4 & Estrato 5 & Estrato 6 & Estrato 7 & Estrato 8 & Total EPH \\
\hline $2015 q 3-1$ & 4.011 .743 & 4.046 .134 & 2.032 .559 & 2.710 .384 & 2.745 .782 & 3.615 .662 & 112.370 & 7.733 .388 & 27.008 .020 \\
$2015 q 3-2$ & 4.126 .154 & 3.984 .458 & 1.908 .944 & 2.710 .421 & 2.745 .884 & 3.686 .528 & 112.381 & 7.733 .389 & 27.008 .158 \\
$2015 q 3-3$ & 4.076 .371 & 4.025 .492 & 2.082 .750 & 2.622 .031 & 2.669 .508 & 3.646 .072 & 110.169 & 7.767 .898 & 27.000 .291 \\
$2015 q 3-4$ & 4.244 .814 & 3.989 .981 & 1.910 .887 & 2.621 .873 & 2.669 .421 & 3.684 .998 & 110.177 & 7.767 .868 & 27.000 .020 \\
$2015 q 4-1$ & 3.956 .158 & 4.088 .321 & 2.023 .313 & 2.741 .175 & 2.763 .699 & 3.662 .883 & 114.384 & 7.723 .394 & 27.073 .327 \\
$2015 q 4-2$ & 4.015 .036 & 3.905 .846 & 2.019 .680 & 2.741 .083 & 2.763 .721 & 3.789 .984 & 114.376 & 7.722 .973 & 27.072 .699 \\
$2015 q 4-3$ & 4.067 .332 & 4.025 .880 & 2.031 .988 & 2.675 .987 & 2.721 .610 & 3.627 .618 & 123.183 & 7.792 .614 & 27.066 .211 \\
$2015 q 4-4$ & 4.129 .897 & 3.968 .861 & 1.965 .404 & 2.676 .11 & 2.721 .735 & 3.688 .906 & 123.184 & 7.792 .292 & 27.066 .390 \\
$2016 q 1-1$ & 4.057 .522 & 4.033 .519 & 2.089 .568 & 2.599 .048 & 2.757 .314 & 3.725 .888 & 110.775 & 7.774 .159 & 27.147 .793 \\
$2016 q 1-2$ & 4.459 .987 & 3.762 .501 & 1.968 .677 & 2.599 .092 & 2.757 .216 & 3.715 .499 & 110.766 & 7.774 .478 & 27.148 .215 \\
$2016 q 1-3$ & 4.034 .819 & 4.031 .512 & 2.085 .157 & 2.693 .531 & 2.744 .325 & 3.725 .190 & 106.260 & 7.714 .683 & 27.135 .477 \\
$2016 q 1-4$ & 4.202 .736 & 3.996 .293 & 1.913 .025 & 2.693 .542 & 2.744 .473 & 3.764 .899 & 106.263 & 7.715 .000 & 27.136 .230 \\
Promedio 2015q3 & 4.114 .770 & 4.011 .516 & 1.983 .785 & 2.666 .177 & 2.707 .649 & 3.658 .315 & 111.274 & 7.750 .636 & 27.004 .122 \\
Promedio 2015q4 & 4.042 .106 & 3.997 .227 & 2.010 .096 & 2.708 .589 & 2.742 .691 & 3.692 .348 & 118.782 & 7.757 .818 & 27.069 .657 \\
Promedio 2016q1 & 4.188 .766 & 3.955 .956 & 2.014 .107 & 2.646 .303 & 2.750 .832 & 3.732 .869 & 108.516 & 7.744 .580 & 27.141 .929 \\
\hline Fuente: elaboración propia basada en SIPA (Ministerio de Trabajo, 2020), ANSES (2020) y EPH (INDEC, 2020d).
\end{tabular}

Tabla C.2. Estimación de ingresos individuales promedio por estrato socio-ocupacional, simulaciones 2015-2016

\begin{tabular}{lccccccccc} 
Período & Estrato 1 & Estrato 2 & Estrato 3 & Estrato 4 & Estrato 5 & Estrato 6 & Estrato 7 & Estrato 8 & Total EPH \\
\hline $2015 q 3-1$ & 736,7 & 11313,3 & 13242,9 & 5498,3 & 8045,9 & 6384,6 & 457,5 & 31,5 & 5036,3 \\
$2015 q 3-2$ & 736,9 & 11834,0 & 13034,5 & 5502,3 & 8049,7 & 6659,6 & 457,9 & 31,9 & 5070,3 \\
$2015 q 3-3$ & 707,1 & 11278,6 & 12755,3 & 5625,1 & 7935,4 & 6230,0 & 1389,9 & 30,6 & 4958,8 \\
$201593-4$ & 707,9 & 11834,0 & 13034,5 & 5623,9 & 7933,5 & 6659,6 & 1389,6 & 31,0 & 5036,6 \\
$2015 q 4-1$ & 717,2 & 10584,0 & 13055,3 & 5881,2 & 8367,8 & 6042,9 & 463,1 & 28,8 & 4956,2 \\
$2015 q 4-2$ & 717,5 & 1137,8 & 12334,6 & 5879,5 & 8361,5 & 6447,8 & 461,7 & 29,0 & 4995,2 \\
$2015 q 4-3$ & 841,2 & 10881,5 & 12788,4 & 5890,1 & 8492,9 & 5916,0 & 812,7 & 34,7 & 4948,0 \\
$2015 q 4-4$ & 841,2 & 11229,5 & 12904,4 & 5887,1 & 8498,5 & 6117,2 & 813,0 & 34,7 & 4996,1 \\
$2016 q 1-1$ & 821,8 & 12531,7 & 14780,8 & 6569,1 & 9193,7 & 7004,1 & 964,8 & 37,9 & 5661,2 \\
$2016 q 1-2$ & 822,5 & 12970,0 & 15059,0 & 6568,3 & 9199,5 & 7476,8 & 965,7 & 38,4 & 5626,0 \\
$2016 q 1-3$ & 906,2 & 12531,7 & 14780,8 & 6540,0 & 9152,5 & 7004,1 & 976,7 & 36,5 & 5682,9 \\
$2016 q 1-4$ & 906,6 & 13145,4 & 15101,8 & 6535,9 & 9158,9 & 7488,8 & 977,0 & 37,0 & 5769,3
\end{tabular}




\begin{tabular}{cccccccccc}
\hline \multicolumn{2}{c}{ Tabla C.2. Estimación de ingresos individuales promedio por estrato socio-ocupacional, simulaciones 2015-2016 } \\
\hline Período & Estrato 1 & Estrato 2 & Estrato 3 & Estrato 4 & Estrato 5 & Estrato 6 & Estrato 7 & Estrato 8 & Total EPH \\
\hline Promedio 2015q3 & 722,1 & 11564,9 & 13016,8 & 5562,4 & 7991,1 & 6483,5 & 923,7 & 31,2 & 5025,5 \\
Promedio 2015q4 & $\mathbf{7 7 9 , 3}$ & 10958,2 & 12770,7 & 5884,5 & 8430,2 & 6131,0 & 637,6 & 31,8 & 4973,9 \\
Promedio 2016q1 & 864,3 & 12794,7 & 14930,6 & 6553,3 & 9176,2 & 7243,5 & 971,0 & 37,5 & 5684,9
\end{tabular}

Fuente: elaboración propia basada en SIPA (Ministerio de Trabajo, 2020), ANSES (2020), Cuentas Nacionales (INDEC, 2020c) y EPH (INDEC, 2020d).

Tabla C.3. Coeficiente de Gini, ingreso per cápita familiar. Estimaciones 2015-2016 con y sin ajustes por tendencia de la ETOI-CABA

\begin{tabular}{ccc}
\hline Período & Sin ajuste por variaciones de ETOI-CABA & Ajustado por ETOI-CABA \\
\hline $2015 q 3-1$ & 0,429 & 0,415 \\
$2015 q 3-2$ & 0,443 & 0,430 \\
$2015 q 3-3$ & 0,420 & 0,407 \\
$2015 q 3-4$ & 0,443 & 0,429 \\
$2015 q 4-1$ & 0,414 & 0,410 \\
$2015 q 4-2$ & 0,422 & 0,418 \\
$2015 q 4-3$ & 0,407 & 0,403 \\
$2015 q 4-4$ & 0,432 & 0,428 \\
$2016 q 1-1$ & 0,418 & 0,419 \\
$2016 q 1-2$ & 0,436 & 0,437 \\
$2016 q 1-3$ & 0,418 & 0,419 \\
$2016 q 1-4$ & 0,441 & 0,442 \\
Promedio 2015q3 & 0,434 & 0,420 \\
Promedio 2015q4 & 0,419 & 0,415 \\
Promedio 2016q1 & 0,428 & 0,429 \\
\hline
\end{tabular}

Fuente: elaboración propia basada en EPH (INDEC, 2020d), ANSES (2020), SIPA (Ministerio de Trabajo, 2020), Cuentas Nacionales (INDEC, 2020c) y ETOI-CABA (Gobierno de la Ciudad de Buenos Aires, 2020b).

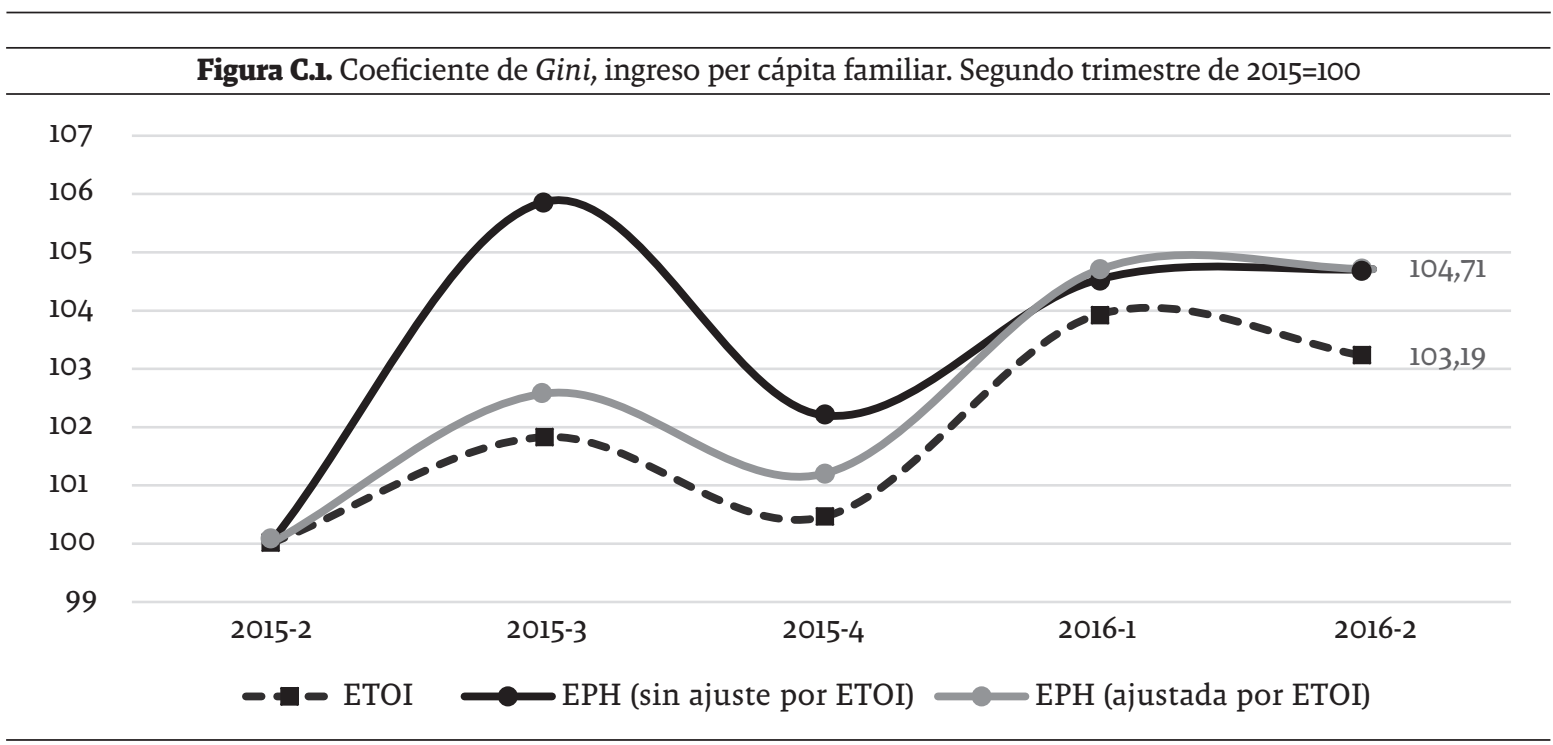

Fuente: elaboración propia basada en EPH (INDEC, 2020d), ANSES (2020), SIPA (Ministerio de Trabajo, 2020), Cuentas Nacionales (INDEC, 2020c) y ETOI-CABA (Gobierno de la Ciudad de Buenos Aires, 2020b). 
Anexo D

\begin{tabular}{|c|c|c|c|c|}
\hline Período & Pobreza trimestral & Pobreza (semestres móviles) & Indigencia (trimestral) & Indigencia (semestres móviles) \\
\hline 200393 & $58,8 \%$ & & $22,1 \%$ & \\
\hline 200394 & $59,7 \%$ & $59,3 \%$ & $21,8 \%$ & $22,0 \%$ \\
\hline $2004 q 1$ & $57,1 \%$ & $58,4 \%$ & $19,1 \%$ & $20,5 \%$ \\
\hline $2004 q 2$ & $59,3 \%$ & $58,2 \%$ & $21,6 \%$ & $20,3 \%$ \\
\hline 200493 & $52,3 \%$ & $55,8 \%$ & $17,3 \%$ & $19,4 \%$ \\
\hline 200494 & $53,6 \%$ & $52,9 \%$ & $16,6 \%$ & $16,9 \%$ \\
\hline $2005 q 1$ & $50,2 \%$ & $51,9 \%$ & $14,8 \%$ & $15,7 \%$ \\
\hline $2005 q 2$ & $52,0 \%$ & $51,1 \%$ & $15,0 \%$ & $14,9 \%$ \\
\hline 200593 & $45,9 \%$ & $48,9 \%$ & $13,8 \%$ & $14,4 \%$ \\
\hline $2005 q 4$ & $47,3 \%$ & $46,6 \%$ & $12,8 \%$ & $13,3 \%$ \\
\hline $2006 q 1$ & $43,9 \%$ & $45,6 \%$ & $13,0 \%$ & $12,9 \%$ \\
\hline $2006 \mathrm{q} 2$ & $43,2 \%$ & $43,6 \%$ & $11,7 \%$ & $12,4 \%$ \\
\hline $2006 q 3$ & $38,0 \%$ & $40,6 \%$ & $10,0 \%$ & $10,9 \%$ \\
\hline $2006 q 4$ & $40,8 \%$ & $39,4 \%$ & $9,7 \%$ & $9,9 \%$ \\
\hline $2007 q 1$ & $36,0 \%$ & $38,4 \%$ & $8,8 \%$ & $9,3 \%$ \\
\hline $2007 q 2$ & $37,9 \%$ & $37,0 \%$ & $10,1 \%$ & $9,4 \%$ \\
\hline $2007 q 3$ & $35,9 \%$ & $36,9 \%$ & $9,5 \%$ & $9,8 \%$ \\
\hline $2007 q 4$ & $39,8 \%$ & $37,9 \%$ & $9,7 \%$ & $9,6 \%$ \\
\hline $2008 q 1$ & $35,1 \%$ & $37,5 \%$ & $9,8 \%$ & $9,7 \%$ \\
\hline $2008 \mathrm{q} 2$ & $37,3 \%$ & $36,2 \%$ & $10,5 \%$ & $10,1 \%$ \\
\hline $2008 \mathrm{q} 3$ & $35,1 \%$ & $36,2 \%$ & $9,5 \%$ & $10,0 \%$ \\
\hline $2008 \mathrm{q} 4$ & $35,1 \%$ & $35,1 \%$ & $8,4 \%$ & $8,9 \%$ \\
\hline $2009 q 1$ & $32,1 \%$ & $33,6 \%$ & $7,9 \%$ & $8,1 \%$ \\
\hline $2009 q 2$ & $35,2 \%$ & $33,7 \%$ & $8,7 \%$ & $8,3 \%$ \\
\hline 2009q3 & $32,0 \%$ & $33,6 \%$ & $8,7 \%$ & $8,7 \%$ \\
\hline $2009 q 4$ & $33,2 \%$ & $32,6 \%$ & $8,3 \%$ & $8,5 \%$ \\
\hline 2010q1 & $30,4 \%$ & $31,8 \%$ & $7,9 \%$ & $8,1 \%$ \\
\hline $2010 q 2$ & $34,3 \%$ & $32,4 \%$ & $9,6 \%$ & $8,7 \%$ \\
\hline 201093 & $30,6 \%$ & $32,5 \%$ & $7,8 \%$ & $8,7 \%$ \\
\hline $2010 q 4$ & $32,6 \%$ & $31,6 \%$ & $8,6 \%$ & $8,2 \%$ \\
\hline 20llql & $29,7 \%$ & $31,1 \%$ & $7,1 \%$ & $7,8 \%$ \\
\hline $2011 q 2$ & $30,9 \%$ & $30,3 \%$ & $8,0 \%$ & $7,5 \%$ \\
\hline 201193 & $27,9 \%$ & $29,4 \%$ & $7,1 \%$ & $7,6 \%$ \\
\hline 201194 & $30,9 \%$ & $29,4 \%$ & $6,4 \%$ & $6,8 \%$ \\
\hline $2012 q 1$ & $28,1 \%$ & $29,5 \%$ & $6,5 \%$ & $6,5 \%$ \\
\hline $2012 q 2$ & $30,6 \%$ & $29,4 \%$ & $7,0 \%$ & $6,8 \%$ \\
\hline 2012q3 & $28,2 \%$ & $29,4 \%$ & $7,0 \%$ & $7,0 \%$ \\
\hline $2012 q 4$ & $29,7 \%$ & $29,0 \%$ & $5,9 \%$ & $6,5 \%$ \\
\hline $2013 q 1$ & $27,3 \%$ & $28,5 \%$ & $5,5 \%$ & $5,7 \%$ \\
\hline $2013 q 2$ & $29,0 \%$ & $28,2 \%$ & $5,9 \%$ & $5,7 \%$ \\
\hline 201393 & $26,2 \%$ & $27,6 \%$ & $6,0 \%$ & $5,9 \%$ \\
\hline 201394 & $28,3 \%$ & $27,3 \%$ & $6,3 \%$ & $6,2 \%$ \\
\hline $2014 q 1$ & $29,1 \%$ & $28,7 \%$ & $6,6 \%$ & $6,5 \%$ \\
\hline $2014 q 2$ & $32,3 \%$ & $30,7 \%$ & $8,1 \%$ & $7,4 \%$ \\
\hline 201493 & $30,6 \%$ & $31,5 \%$ & $6,7 \%$ & $7,4 \%$ \\
\hline 201494 & $31,1 \%$ & $30,9 \%$ & $6,9 \%$ & $6,8 \%$ \\
\hline $2015 q 1$ & $28,4 \%$ & $29,8 \%$ & $6,1 \%$ & $6,5 \%$ \\
\hline $2015 q 2$ & $30,7 \%$ & $29,6 \%$ & $5,5 \%$ & $5,8 \%$ \\
\hline 201593 & $25,5 \%$ & $28,1 \%$ & $4,3 \%$ & $4,9 \%$ \\
\hline
\end{tabular}


Tabla D.1. Tasa de pobreza e indigencia, serie comparable

\begin{tabular}{ccccc}
\hline \multicolumn{5}{c}{ Tabla D.1. Tasa de pobreza e indigencia, serie comparable } \\
\hline Período & Pobreza trimestral & Pobreza (semestres móviles) & Indigencia (trimestral) & Indigencia (semestres móviles) \\
\hline $2015 q 4$ & $28,3 \%$ & $26,9 \%$ & $5,1 \%$ & $4,7 \%$ \\
$2016 q 1$ & $28,7 \%$ & $28,5 \%$ & $6,3 \%$ & $5,7 \%$ \\
$2016 q 2$ & $32,2 \%$ & $30,5 \%$ & $6,2 \%$ & $6,2 \%$ \\
$2016 q 3$ & $30,7 \%$ & $31,4 \%$ & $6,6 \%$ & $6,4 \%$ \\
$2016 q 4$ & $30,0 \%$ & $30,3 \%$ & $5,7 \%$ & $6,1 \%$ \\
$2017 q 1$ & $27,7 \%$ & $28,9 \%$ & $6,1 \%$ & $5,9 \%$ \\
$2017 q 2$ & $29,4 \%$ & $28,6 \%$ & $6,2 \%$ & $6,2 \%$ \\
$2017 q 3$ & $25,0 \%$ & $27,2 \%$ & $5,0 \%$ & $5,6 \%$ \\
$2017 q 4$ & $26,3 \%$ & $25,7 \%$ & $4,5 \%$ & $4,8 \%$ \\
$2018 q 1$ & $25,5 \%$ & $25,9 \%$ & $4,9 \%$ & $4,7 \%$ \\
$2018 q 2$ & $29,1 \%$ & $27,3 \%$ & $4,9 \%$ & $4,9 \%$ \\
$2018 q 3$ & $28,1 \%$ & $28,6 \%$ & $5,9 \%$ & $5,4 \%$ \\
$2018 q 4$ & $35,5 \%$ & $32,0 \%$ & $7,4 \%$ & $6,7 \%$ \\
$2019 q 1$ & $34,3 \%$ & $34,9 \%$ & $7,1 \%$ & $7,2 \%$ \\
$2019 q 2$ & $36,6 \%$ & $35,4 \%$ & $8,2 \%$ & $7,6 \%$ \\
$2019 q 3$ & $33,1 \%$ & $34,8 \%$ & $7,6 \%$ & $7,9 \%$
\end{tabular}

Nota: Las celdas en gris corresponden a las estimaciones de trimestres faltantes.

Fuente: Elaboración propia basada en datos de EPH (INDEC, 2020d), SIPA (Ministerio de Trabajo, 2020), ANSES (2020), Cuentas Nacionales (INDEC, 2020c), ETOI-CABA (Gobierno de la Ciudad de Buenos Aires, 2020b), IPC (INDEC, 2020e), IPC-San Luis (Gobierno de San Luis, 2020), IPC-CABA (Gobierno de la Ciudad de Buenos Aires, 2020a) e IPC-Córdoba (Gobierno de la provincia de Córdoba, 2020).

\section{Referencias bibliográficas}

ANSES -Administración Nacional de la Seguridad Social-. (2020). Datos abiertos. Recuperado de https://www.anses.gob.ar/institucional/datos-abiertos

Arakaki, A. (2016). Cambios recientes en la encuesta permanente de hogares. Análisis de la actualización de las proyecciones poblacionales y la muestra maestra. Documento de trabajo del Centro de estudios sobre Población, Empleo y Desarrollo (CEPED). Recuperado de http://bibliotecadigital.econ.uba.ar/ download/docin/docin_ceped_d_022.pdf

Beccaria, L., y Maurizio, R. (2017). Mercado de trabajo y desigualdad en Argentina. Un balance de las últimas tres décadas. Revista Sociedad, (37), 15-41.

CEDLAS -Centro de Estudios Distributivos, Laborales y Sociales-. (2018). La pobreza en Argentina: recuperando la comparabilidad. Blog del CEDLAS. Recuperado de http://www.cedlas.econo.unlp. edu.ar/wp/la-pobreza-en-argentina-recuperando-la-comparabilidad/

CIFRA-CTA -Centro de Investigación y Formación de la República Argentina-Central de Trabajadores de la Argentina-. (2015). Principales resultados de pobreza e indigencia 2003-2015. Recuperado de http://www.cta.org.ar/IMG/pdf/03-ie-_noviembre_2015-pobreza.pdf

Gobierno de la Ciudad de Buenos Aires. (2020a). Índice de Precio al Consumidor (IPC). Recuperado de https:// www.estadisticaciudad.gob.ar/eyc/wp-content/uploads/2019/05/Principales_aperturas_indices.xlsx

Gobierno de la Ciudad de Buenos Aires. (2020b). Encuesta Trimestral de Ocupación e Ingresos (ETOI). Recuperado de https:/www.estadisticaciudad.gob.ar/eyc/wp-content/uploads/2018/05/ETOI_I_ IPCFP_G.xlsx 
Gobierno de la provincia de Córdoba. (2020). Índice de Precios al Consumidor (IPC). Recuperado de https://datosestadistica.cba.gov.ar/dataset/fedc5285-5517-41aa-9095-bb62c6dbc485/ resource/2b4a7c60-1c8a-45bl-be8f-2bd59bfe2364/download/ipc-cba-enero-.xlsx

Gobierno de San Luis. (2020). Índice de Precio al Consumidor (IPC). Recuperado de https://www.ieric. org.ar/fileHandler.ashx? type $=$ contenidosID\&file $=13958$

INDEC -Instituto Nacional de Estadística y Censos-. (2004). Actualización de la metodología oficial de cálculo de las Líneas de Pobreza. Documento presentado en el $13^{\circ}$ Taller Regional "La construcción de líneas de pobreza en América Latina. Metodología y Práctica", Lima, Perú.

INDEC -Instituto Nacional de Estadística y Censos-. (2009). Ponderación de la muestra y tratamiento de valores faltantes en la variable de ingreso de la Encuesta Permanente de Hogares. Metodología INDEC $N^{o}$ 15. Recuperado de https://www.indec.gov.ar/nuevaweb/cuadros/4/eph_metodologia_15. pdf

INDEC -Instituto Nacional de Estadística y Censos-. (2016). La medición de la pobreza y la indigencia en la Argentina. Metodología INDEC $N^{\circ}$ 22. Recuperado de http://www.indec.gob.ar/ftp/cuadros/ sociedad/EPH_metodologia_22_pobreza.pdf

INDEC -Instituto Nacional de Estadística y Censos-. (2020a). Canasta básica. Recuperado de https:// www.indec.gob.ar/indec/web/Nivel3-Tema-4-43

INDEC-Instituto Nacional de Estadística y Censos-. (2020b). Censos Nacionales de Población y Vivienda. Recuperado de https://www.indec.gob.ar/indec/web/Nivel3-Tema-2-41

INDEC -Instituto Nacional de Estadística y Censos-. (2020c). Cuentas Nacionales. Recuperado de https://sitioanterior.indec.gob.ar/ftp/cuadros/economia/sh_VBP_VAB_06_19.xls

INDEC -Instituto Nacional de Estadística y Censos-. (2020d). Encuesta Permanente de Hogares (EPH). Recuperado de https://www.indec.gob.ar/indec/web/Institucional-Indec-BasesDeDatos

INDEC -Instituto Nacional de Estadística y Censos-. (2020e). Índice de precios al consumidor (IPC). Recuperado de https://www.indec.gob.ar/indec/web/Nivel4-Tema-3-5-31

Ministerio de Trabajo. (2020). Estudios y Estadisticas Laborales. Sistema Integrado previsional Argentino (SIPA). Recuperado de http://www.trabajo.gob.ar/estadisticas/trabajoregistrado/

ODSA-UCA -Observatorio de la Deuda Social Argentina-Pontificia Universidad Católica Argentina-. (2016). Pobreza y desigualdad en la Argentina urbana 2010-15. Tiempos de balance. Documento de Trabajo. Recuperado de http://wadmin.uca.edu.ar/public/ckeditor/2016-Obs-Informe-nl-PobrezaDesigualdad-Ingresos-Argentina-Urbana-Presentacion.pdf

ODSA-UCA -Observatorio de la Deuda Social Argentina-Pontificia Universidad Católica Argentina-. (18-20 de septiembre, 2019). Tiempo de balances. Pobreza, exclusión y desigualdad en la Argentina urbana (2010-2017). Ponencia presentada en "XV Jornadas Argentinas de Estudios de Población", Universidad Nacional de San Juan, San Juan, Argentina. Recuperado de http:// wadmin.uca.edu.ar/public/ckeditor/Observatorio\%20Deuda\%20Social/Presentaciones\%20 2018/2018/2018-Observatorio-Pobreza-Desigualdad-Dialogos.pdf

Tornarolli, L. (2018). Series comparables de indigencia y pobreza: una propuesta metodológica. Documentos de trabajo 226, CEDLAS. Recuperado de http://www.cedlas.econo.unlp.edu.ar/wp/wpcontent/uploads/doc_cedlas226.pdf 
Vera, J., y Salvia, A. (2019). Pobreza y desigualdad monetaria en los hogares urbanos de la Argentina a partir de la Encuesta de la Deuda Social Argentina (2010-2018). Revisión, actualización metodológica y nuevos resultados. Documento de Trabajo del ODSA. Recuperado de http://wadmin.uca.edu.ar/ public/ckeditor/Observatorio\%20Deuda\%20Social/Documentos/2019/2019-OBSERVATORIODOCUMENTO-TRABAJO-POBREZA-DESIGUALDAD-MONETARIA-MAYO-VF.pdf

Zack, G. (2016). El efecto asimétrico del ciclo económico sobre las condiciones sociales en la Argentina (2003-2015). Revista Estudios Económicos, XXXIII(67), 67-94. 